\title{
Toward a Common Terminology for the Gyri and Sulci of the Human Cerebral Cortex
}

\author{
Hans J. ten Donkelaar ${ }^{1 \star \dagger}$, Nathalie Tzourio-Mazoyer ${ }^{2 \dagger}$ and Jürgen K. Mai ${ }^{3+}$ \\ ${ }^{1}$ Department of Neurology, Donders Center for Medical Neuroscience, Radboud University Medical Center, Nijmegen, \\ Netherlands, ${ }^{2}$ IMN Institut des Maladies Neurodégénératives UMR 5293, Université de Bordeaux, Bordeaux, France, \\ ${ }^{3}$ Institute for Anatomy, Heinrich Heine University, Düsseldorf, Germany
}

OPEN ACCESS

Edited by:

Marcello Rosa,

Monash University, Australia

Reviewed by:

Muhammad A. Spocter,

Des Moines University, United States

Charles R. Watson,

Curtin University, Australia

${ }^{*}$ Correspondence:

Hans J. ten Donkelaar hans.tendonkelaar@radboudumc.nl;

hitendonkelaar@gmail.com

†These authors have contributed equally to this work

Received: 08 September 2018 Accepted: 16 October 2018

Published: 19 November 2018

Citation:

ten Donkelaar HJ, Tzourio-Mazoyer N and Mai JK (2018) Toward a Common

Terminology for the Gyri and Sulci of the Human Cerebral Cortex.

Front. Neuroanat. 12:93.

doi: 10.3389/fnana.2018.00093
The gyri and sulci of the human brain were defined by pioneers such as Louis-Pierre Gratiolet and Alexander Ecker, and extensified by, among others, Dejerine (1895) and von Economo and Koskinas (1925). Extensive discussions of the cerebral sulci and their variations were presented by Ono et al. (1990), Duvernoy (1992), Tamraz and Comair (2000), and Rhoton (2007). An anatomical parcellation of the spatially normalized single high resolution T1 volume provided by the Montreal Neurological Institute (MNI; Collins, 1994; Collins et al., 1998) was used for the macroscopical labeling of functional studies (Tzourio-Mazoyer et al., 2002; Rolls et al., 2015). In the standard atlas of the human brain by Mai et al. (2016), the terminology from Mai and Paxinos (2012) is used. It contains an extensively analyzed individual brain hemisphere in the $\mathrm{MNI}$ space. A recent revision of the terminology on the central nervous system in the Terminologia Anatomica (TA, 1998) was made by the Working Group Neuroanatomy of the Federative International Programme for Anatomical Terminology (FIPAT) of the International Federation of Associations of Anatomists (IFAA), and posted online as the Terminologia Neuroanatomica (TNA, 2017: http://FIPAT.library.dal.ca) as the official FIPAT terminology. This review deals with the various terminologies for the cerebral gyri and sulci, aiming for a common terminology.

Keywords: terminology, gyri, sulci, cerebral cortex, human brain

\section{INTRODUCTION}

Although the gyri and sulci of the human brain were already beautifully illustrated by Vicq d'Azyr (1786) and von Soemmerring (1791), they were named and defined by Gratiolet (1854), Huschke (1854), Ecker (1869), Pansch (1868, 1879), Jensen (1871), Wernicke (1876), Eberstaller (1884, 1890), and Brissaud (1893), and extensified by, among others, Dejerine (1895), Retzius (1896), von Economo and Koskinas (1925), and Rose (1935). More recently, extensive discussions of the cerebral sulci and their variations were presented by Ono et al. (1990), Duvernoy (1992), Tamraz and Comair (2000), and Rhoton (2007). An anatomical parcellation of the spatially normalized single high resolution T1 volume provided by the Montreal Neurological Institute (MNI) was used for the macroscopical labeling of functional studies (Tzourio-Mazoyer et al., 2002; Rolls et al., 2015), using largely the Dejerine terminology. The previously much used Talairach atlas (Talairach and Tournoux, 1988) proved to be rather inaccurate for the cytoarchitectonic allocation of functional activations (Tzourio-Mazoyer et al., 2002; Eickhoff et al., 2005). In the standard atlas of the human 
brain by Mai et al. (2016), the terminology from Mai and Paxinos (2012) is used. It contains an individual brain hemisphere in the MNI-space. In a recent pocket atlas (Mai and Majtanik, 2017), a probabilistic neuroanatomy of 152 individuals was presented to which the main atlas is registered. Mai and colleagues used the Brodmann (1909) and von Economo and Koskinas (1925) subdivisions of the cerebral cortex. A comprehensive cellularresolution atlas of the adult human brain (Ding et al., 2016) presents the first digital human brain atlas across a complete adult female brain. The terminology used largely follows Brodmann terminology.

Recently, a revision of the terminology on the central nervous system in the Terminologia Anatomica (TA, 1998) was made by the Working Group Neuroanatomy of the Federative International Programme for Anatomical Terminology (FIPAT) of the International Federation of Associations of Anatomists (IFAA), and posted online as the Terminologia Neuroanatomica (TNA, 2017: http://FIPAT.library.dal.ca; for an introductory paper, see ten Donkelaar et al., 2017) as the official FIPAT terminology. This review deals with the various terminologies for the cerebral gyri and sulci on the superolateral, inferomedial, and basal surfaces of the cerebrum, aiming for a common terminology. It combines the data from the TNA (2017), an illustrated version (ten Donkelaar et al., 2018) and additional terms found in preparing this review.

\section{BRIEF REVIEW OF THE LITERATURE}

In Figure 1, the wealth of gyri and sulci of the human cerebral cortex as distinguished by von Economo and Koskinas (1925) is shown. The gyri of the cerebral lobes are indicated by the classical numbering such as F1-F3, T1-T4, and the sulci without capitals (f1, f2, etc). Clearly visible are the first and second intermediate parietal sulci of Jensen and Eberstaller (s.imdI and s.imdII, respectively) as well as the frontomarginal sulcus of Wernicke with various components. Many of the smaller or infrequent sulci were forgotten, several of which were reintroduced in the recent human brain mapping era and in the TNA. The Supplementary Table 1 contains a list of synonyms and eponyms for the cerebral gyri and the Supplementary Table 2 those of the main sulci.

Terminological differences used in Tzourio-Mazoyer's approach (Tzourio-Mazoyer et al., 2002; Rolls et al., 2015; Figure 2) vs. the Terminologia Anatomica (TA, 1998) concern the use of eponyms such as Rolandic operculum, Sylvian fissure and Heschl's gyrus, and the use of gyrus instead of lobule for the superior and inferior parietal lobules.

In the atlas of Mai et al. (2016) and the recent pocket atlas by Mai and Majtanik (2017), the use of the term fissure is advocated for the lateral, parietooccipital and hippocampal sulci. In the BNA (1895), the terms fissurae cerebri lateralis, collateralis, parietooccipitalis, calcarina, and hippocampi were used. In the JNA (1936), only the lateral, Sylvian fissure remained as fissure. This was corrected in the PNA (1955) and later editions, and for the cerebrum, the term fissure is in use only for the interhemispheric fissure. Therefore, the term fissure should not have been advocated anymore.
Minor differences in Mai et al. (2016) are the use of the terms central operculum for the subcentral gyrus, anterior intermediate parietal sulcus for the first intermediate parietal sulcus of Jensen (see also Zlatkina and Petrides, 2014), medial occipitotemporal gyrus as a common term for the lingual gyrus and the parahippocampal gyrus, periinsular sulcus for the circular sulcus of the insula, and a rather extensive terminology for the opercula, including frontal, frontoparietal, and temporal opercula (Figure 3). Their frontoparietal operculum includes the anterior central (precentral) operculum, the subcentral gyrus, the posterior central (postcentral) operculum, and the parietal operculum. The first three collectively may belong to the subcentral gyrus.

In their atlas of the human brain in MNI space, Mai et al. (2016) presented photographs of cell-stained sections of the right hemisphere of a 24-year-old male from the Vogtcollection in Düsseldorf (Vogt and Vogt, 1919). Schematic drawings show delineations of the cortex, which are based on the original maps of Brodmann (1909). The surfacebased maps by Van Essen (2005); Van Essen et al. (2012) were modified by manually estimating areal boundaries on the atlas drawing and transforming them on the surface of the 3D reconstruction. Nieuwenhuys et al. (2015) adapted the standard brain, generated from the colin27 brain (http:// www.bic.mni.mcgill.ca/ServicesAtlases/Colin27). In Figures 4, 5, gyri and sulci are shown for the lateral and medial aspects, respectively. The colin27 image is the result of averaging 27 linearly registered high-resolution T1-weighted scans of the same individual (Collins, 1994; Collins et al., 1998; Holmes et al., 1998), matched to the MNI305-space (Mazziota et al., 2001). Several neuroimaging software systems adopted the colin27 template as the standard reference. Nieuwenhuys et al. (2015) noted a few peculiarities of the colin27 template brain: (1) the Broca area of the inferior frontal gyrus is very large, but the middle frontal gyrus is relatively narrow; (2) the superior temporal sulcus is not continuous with the groove marking the cortex of the angular gyrus; (3) both the collateral and cingulate sulci are interrupted, and the posterior part of the cingulate sulcus shows an unusual zigzag course; and (4) the upper surface of the splenium of the corpus callosum has a remarkable bump. It may be added that no attempt was made to subdivide the lateral aspect of the occipital lobe, and that the fairly constant frontomarginal sulcus is absent.

In this review, the terminology of the recent TNA (2017) is presented along with short descriptions and currently used synonyms, and summarized in Tables 1-3. Both English and Latin official terms from the TNA are used. The sulci of the cerebral cortex can be divided into interlobar sulci, separating the cerebral lobes, and lobar sulci present in a lobe.

\section{SUPEROLATERAL SURFACE OF THE CEREBRAL HEMISPHERE}

The lateral aspect of the cerebrum (Figure 6; and Table 1) shows two interlobar sulci: the lateral and central sulci. The lateral sulcus (sulcus lateralis of Sylvius), known for a long time as the Sylvian fissure, between the frontal and temporal lobes, has three branches: the anterior (ramus anterior) or horizontal 

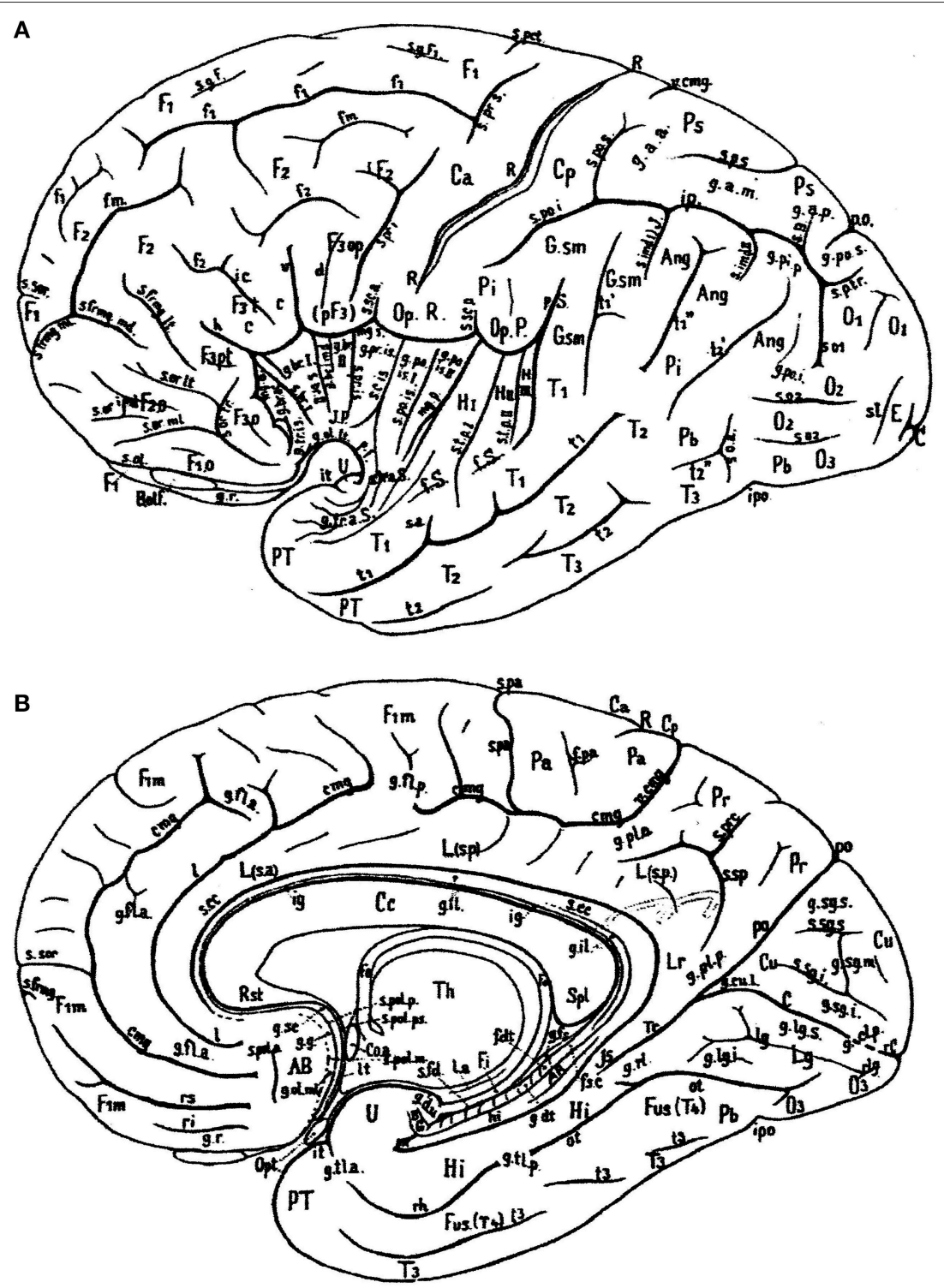

FIGURE 1 | Sulcal pattern in the human cerebral cortex: (A) Lateral aspect; (B) medial aspect (after von Economo and Koskinas, 1925). $A B$, area parolfactoria of Broca; Ang, angular lobule; $A R$, gyri of Andreas Retzius; $B B$, band of Broca; $B G$, bandelette of Giacomini; $B$.olf, olfactory bulb; $C$, calcarine fissure; $C a, C p$, anterior and posterior central gyri; $C c$, corpus callosum; Coa, anterior commissure; $C$, cuneus; $\mathrm{cmg}$, callosomarginal sulcus; $d$, diagonal sulcus of Eberstaller; $E$, descending occipital gyrus of Ecker; F1, F2, F3, first, second and third frontal gyri; F3o, F3op, F3pt, F3t, orbital, opercular, pretriangular, and triangular parts of F3; f1, f2, superior and inferior frontal sulci; $f . d t$, fascia dentata; f.m, middle frontal sulcus; fo, fornix; f.pa, paracentral fossa; fs. C, fasciola cinerea; f.Sy, Sylvian fissure; Fus (T4), fusiform gyrus; g.ant.a, g.ant.d, g.ant.prc, anticentral, antidiagonal and antiprecentral gyrus of operculum; Gsm, supramarginal lobule; g.a.a., g.a.m., g.a.p., arcuate gyri of anterior, middle and posterior superior parietal lobule; g.amb, gyrus ambiens; g.br.a., g.br.l, II, III, g.br.imd, accessory short, first, second and third short and intermediate short gyri of insula; g.cl.p., posterior cuneolingual gyrus; g.dt, dentate gyrus; g.d.u., digital gyri of uncus; g.fl.a., g.fl.p., anterior and posterior frontolimbic gyri; g.fs, fasciolar gyrus; g.g, geniculate gyrus; g.il, intralimbic gyrus; g.lg.i, g.lg.s, inferior and superior lingual gyri; g.ol.lt, g.ol.ml, lateral and medial olfactory gyri; g.pip, posterior inferior parietal gyrus; g.pl.a, g.pl.p, anterior and posterior parietolimbic gyrus; g.po.i, g.po.s, inferior and superior parieto-occipital gyrus; g.po.is.l, g.po.is.Il, first and second postcentral gyrus of insula; g.pr.is, precentral gyrus of isthmus; g.r, straight gyrus; g.rl, retrolimbic gyrus; g.sc, subcallosal gyrus; g.sg.i, g.sg.m, g.sg.s, inferior, middle, and superior sagittal gyrus of cuneus; g.sml, semilunar gyrus; g.str, subtriangular gyrus of operculum; g.tl.a, g.tl.p, anterior and posterior temporolimbic gyrus; g.tr.a.S, anterior transverse temporal gyri of Schwalbe; g.tr.is, transverse gyrus of insula; g.tr.op.l, g.tr.op.Il, g.tr.op.IIl, first, second and third transverse gyrus of parietal operculum; H.I, H.II, first and second gyrus of Heschl; Hi, hippocampal gyrus; $h$, horizontal branch of Sylvian fissure; $h i$, hippocampal fissure; Is, isthmus; ic, incisura capiti; ig, indusium griseum; ip, interparietal sulcus; ipo, preoccipital incisure; it, temporal incisure; Lg, lingula; L.s.a, L.s.p, anterior and posterior part of superior limbic gyrus; Lr, retrosplenial part of limbic gyri; I, intralimbic sulcus; I.a, lamina affixa; I.g, lingual sulcus; It, lamina terminalis; mg.a, mg.p, anterior and posterior margin of circular sulcus of insula; $01, \mathrm{O}, \mathrm{O} 3$, first, second and third occipital gyrus; Op.P, parietal operculum; Op.R, frontal operculum of Rolando; Opt, optic nerve; ot, occipitotemporal (collateral) fissure; Pa, paracentral lobule; Pb, basal parietal region; Pi, inferior parietal lobule; Pr, precuneus; Ps, superior parietal lobule; PT, temporopolar gyrus; p.f, falciform incisure; po, parieto-occipital fissure; $p . S y$, posterior branch of Sylvian fissure; $R$, sulcus of Rolando; 
FIGURE 1 | Rst, rostrum of corpus callosum; rC, retrocalcarine fissure; rh, rhinal fissure; ri, rs, inferior and superior rostral sulcus; rl, retrolingual sulcus; Spl, splenium of corpus callosum; s.a, acoustic sulcus; s.B, sulcus of Brissaud; s.br.l, s.br.ll, first and second short sulcus of insula; s.cc, sulcus of corpus callosum; s.c.is, central sulcus of insula; s.fd, fimbriodentate sulcus; s.frmg.ml, s.frmg.md, s.frmg.lt, medial, middle, and lateral frontomarginal sulcus; s.g.F1, sulcus of first frontal gyrus; s.imdl, s.imdll, first (of Jensen) and second (of Eberstaller) intermediate sulcus; s.l, lunate sulcus; so1, so2, first and second occipital sulcus; s.ol olfactory sulcus; s.or.imd, s.or.lt, s.or.ml, s.or.tr, intermediate, lateral, medial, and transverse orbital sulcus; s.pa, paracentral sulcus; s.po.i, s.po.s, inferior and posterior postcentral sulcus; s.po.is postcentral sulcus of isthmus; s.pol.a, s.pol.m, s.pol.p, s.pol.ps, anterior, middle, posterior, and postremal paraolfactory sulcus; s.prc, precuneate sulcus; s.prd, prediagonal sulcus; s.pr.i, s.pr.s, inferior and superior precentral sulcus; s.pr.is, precentral sulcus of insula; s.p.s, s.p.tr, superior and transverse parietal sulcus; s.rh.i, internal rhinal sulcus; s.san, semianular sulcus; s.sc.a, s.sc.p, anterior and posterior subcentral sulcus; s.sg.i, s.gs.s, inferior and superior sagittal sulcus of cuneus; s.so, suboccipital sulcus; s.sor, supraorbital sulcus; s.sp, subparietal sulcus; s.tp.l, s.tp.ll, first and second deep temporal sulcus; s.tr.a.S, anterior transverse temporal sulci of Schwalbe; s.tr.op.l, s.tr.op.ll, first and second transverse sulcus of parietal operculum; T1, T2, T3, first, second and third temporal sulcus; Th, thalamus; Tr, trunk of the parieto-occipital and calcarine fissures; Tr.o, olfactory trigonum; Tu.o, olfactory tubercle; $t 1$, $t 2, t 3$, first, second and third temporal sulci; $U$, uncus; $v$, ventral branch of the Sylvian fissure; $v . c m g$, vertical branch of callosomarginal sulcus.

ramus, the ascending (ramus ascendens) or vertical ramus and the posterior ramus (ramus posterior), separating the parietal and temporal lobes. The central sulcus (sulcus centralis of Rolando) separates the frontal and parietal lobes. It is not a straight line but forms two arches from the superior margin of the hemisphere downwards to the lateral sulcus, the genu superior and the genu inferior (Broca, 1878a). The upper arch borders a "knob," which protrudes posteriorly, and contains the hand area of the somatosensory cortex (Rumeau et al., 1994; Yousry et al., 1997). The parietooccipital sulcus (sulcus parietooccipitalis of Gratiolet) indicates the border between the parietal and occipital lobes superiorly, and the preoccipital notch (incisura preoccipitalis of Meynert) marks that border inferiorly.

The frontal lobe (lobus frontalis) shows the following gyri: the superior, middle and inferior frontal gyri (gyrus frontalis superior, -medius, and -inferior), classically numbered F1, F2, and F3, separated by superior and inferior frontal sulci (sulcus frontalis superior and-inferior, classically numbered $\mathrm{f} 1$ and $\mathrm{f} 2$, see Figure 1), and the precentral gyrus (gyrus precentralis). The central sulcus usually does not reach the lateral sulcus, and is separated from it by a short gyrus, the subcentral gyrus (gyrus subcentralis), delimited in front and behind by the anterior and posterior subcentral sulci (sulcus subcentralis anterior andposterior), respectively, as distinguished by Dejerine (1895); Testut and Latarjet (1948). The subcentral gyrus is also known as the central or Rolandic operculum. The inferior frontal gyrus comprises three parts, orbital, triangular and opercular (pars orbitalis, pars triangularis and pars opercularis). The opercular part forms the frontal operculum. Occasionally, the diagonal sulcus (sulcus diagonalis of Eberstaller) can divide the opercular part of the inferior frontal gyrus into two parts. The triangular part may also be indented from above by a radiate sulcus (sulcus radiatus of Eberstaller). The orbital part is continuous with the basal surface of the frontal lobe, where it merges with the lateral orbital gyrus. The triangular and opercular parts form together the motor language area of Broca (1863); Amunts et al. (1999); Amunts and Zilles (2012). Recent mapping approaches based on cytoarchitecture, transmitter receptor distribution and connectivity revealed a highly differentiated segregation of this region (Amunts and Zilles, 2012). The frontomarginal sulcus (sulcus frontomarginalis of Wernicke) is fairly constant, found at the frontal pole, and connected posteriorly with the middle frontal sulcus. It has two branches, one deep medial branch that borders the frontopolar gyri, and a shallow lateral branch that separates the frontomarginal sulcus from the medial frontal gyrus and the orbital part of the inferior frontal gyrus, respectively. The frontopolar area (area frontopolaris) at the frontal pole (polus frontalis) shows three frontopolar gyri, superior, middle, and inferior, that are clearly separated by limiting sulci, interposed between the superior frontal gyrus and the frontomarginal gyrus. Bludau et al. (2014) distinguished two cytoarchitectonically and functionally distinct areas: the lateral frontopolar area 1 (Fpl) and the medial frontopolar area 2 (Fp2).

The temporal lobe (lobus temporalis) is formed by the superior, middle and inferior temporal gyri (gyrus temporalis superior, -medius, and - inferior), classically numbered T1, T2, and T3, separated by the superior and inferior temporal sulci (sulcus temporalis superior and - inferior, classically numbered $\mathrm{t} 1$ and $\mathrm{t} 2$ ). The temporopolar cortex (cortex temporopolaris) at the temporal pole (polus temporalis) is a heterogenous region, situated between isocortex laterally, proisocortex in caudorostral continuation and paleocortex caudodorsally (Ding et al., 2009; Blaizot et al., 2010).

On the upper surface of the superior temporal gyrus (Figure 7), forming the temporal operculum, the planum polare, the anterior and posterior transverse gyri (gyrus temporalis transversus anterior and - posterior of Heschl) and the planum temporale can be distinguished, separated by sulci. The anterior transverse temporal sulcus (sulcus temporalis transversus anterior) separates the planum polare from the transverse temporal gyri of Heschl, the two transverse temporal gyri are subdivided by the intermediate transverse temporal sulcus (sulcus temporalis transversus intermedius), and the posterior transverse temporal sulcus (sulcus temporalis transversus posterior) separates the posterior transverse temporal gyrus from the planum temporale. There is usually one transverse gyrus of Heschl on the left and two on the right (Heschl, 1878; Marie et al., 2015; Tzourio-Mazoyer and Mazoyer, 2017). These transverse gyri contain the primary auditory cortex. The planum temporale is on the left usually larger than on the right (von Economo and Horn, 1930; Geschwind and Levitsky, 1968; Galaburda et al., 1978; Ide et al., 1999; TzourioMazoyer and Mazoyer, 2017). The posterior part of the superior temporal gyrus forms the sensory or receptive language area of Wernicke (1874).

The temporal lobe is the location of strong asymmetries of its surface with a strong leftward asymmetry of the planum temporale (von Economo and Horn, 1930; Geschwind and 

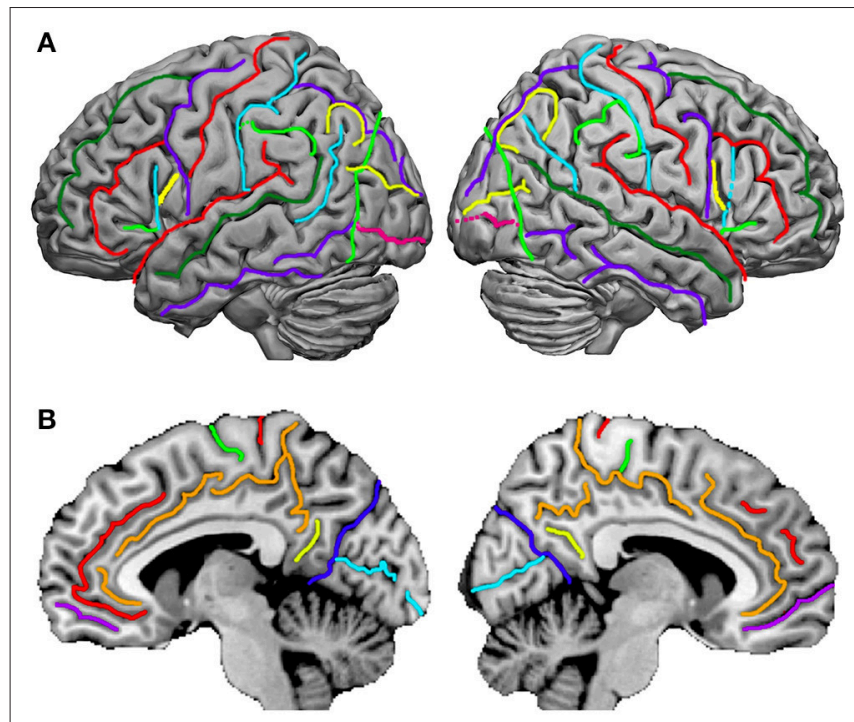

C
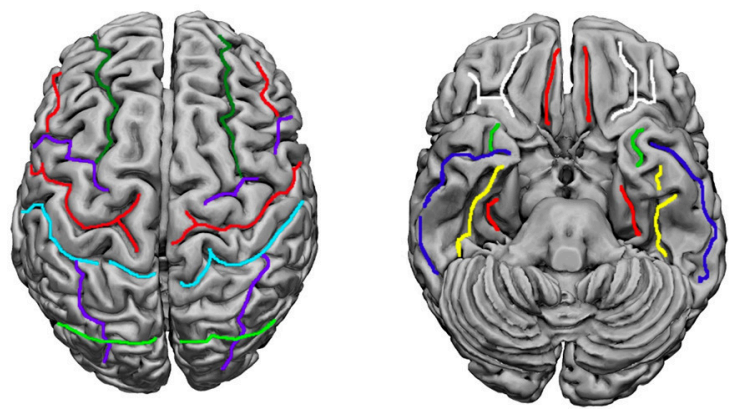

FIGURE 2 | Sulci definition on the 3-D renderings of the T1 MNI single subject brain: (A) Lateral view; left hemisphere on the left. From the frontal pole to the occipital pole, the following sulci are indicated: the superior frontal sulcus (dark green), the inferior frontal sulcus (red), the anterior, horizontal ramus of the lateral, Sylvian sulcus (light green), the ascending, vertical ramus of the lateral sulcus (cyan), the diagonal sulcus (yellow), the precentral sulcus (purple), the central, Rolandic sulcus (red), the postcentral sulcus (cyan), the intraparietal and intraoccipital sulci (purple), the anterior limit of the occipital lobe, corresponding in its inferior part to the anterior occipital sulcus (light green), the transverse occipital sulcus (yellow), and the inferior occipital sulcus (pink). (B) medial view; from the frontal to the occipital pole: the paracingulate sulcus $(r e d)$, the cingulate sulcus (orange), the anterior rostral sulcus (purple), the paracentral sulcus (light green), the central, Rolandic sulcus (red), the marginal ramus (orange), the subparietal sulcus (yellow), the parieto-occipital sulcus (b/ue), and the calcarine sulcus (cyan). (C) At the left, superior view: the superior frontal sulcus (dark green) runs in the same direction and is symmetric in an horizontal plane with the intraoccipital sulcus (purple); the central, Rolandic sulcus (red), the precentral sulcus (purple), and the postcentral sulcus (cyan) run parallel. At the right, basal view: in the frontal lobe the orbital (white) and olfactory (red) sulci are depicted, and in the temporal lobe, the rhinal sulcus (light green), the inferior temporal sulcus (dark blue), the occipitotemporal sulcus (yellow) and the collateral sulcus (red). Adapted from Tzourio-Mazoyer et al. (2002).

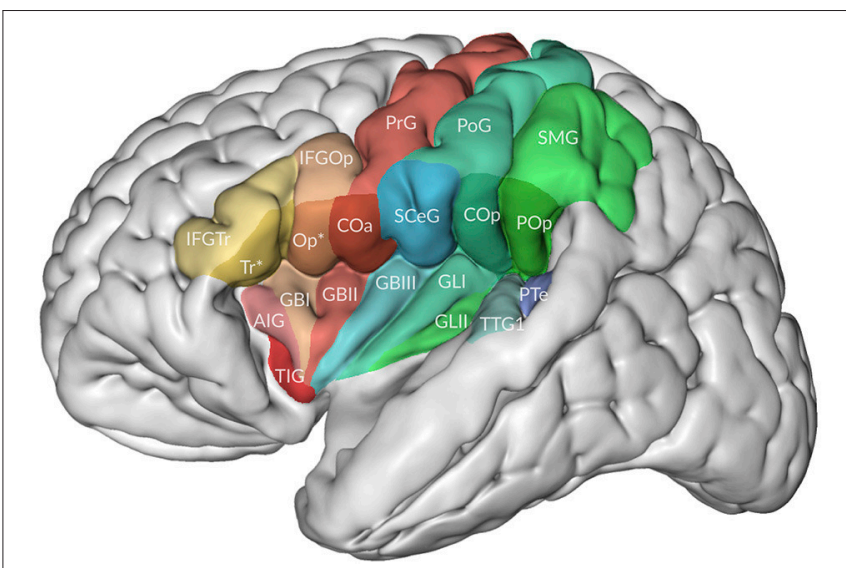

FIGURE 3 | The relation of the opercula to the insula. Adapted from Mai and Majtanek (2017; kindly provided by Milan Majtanik, Düsseldorf). AIG, accessory insular gyrus; COa, Cop, anterior (precentral) and posterior (postcentral) opercula; GBI-III, short insular gyri; GLI-II, long insular gyri; IFGOp, with $O p^{*}$, IFGTr, with $T r^{*}$ opercular and triangular parts of inferior frontal gyrus with opercular and triangular parts of frontal operculum, POG, postcentral gyrus; POp, parietal operculum; PrG, postcentral gyrus; PTe, planum temporale; SCeG, subcentral gyrus; SMG, supramarginal gyrus; TIG, transverse insular gyrus; TTG1, anterior transverse temporal gyrus.

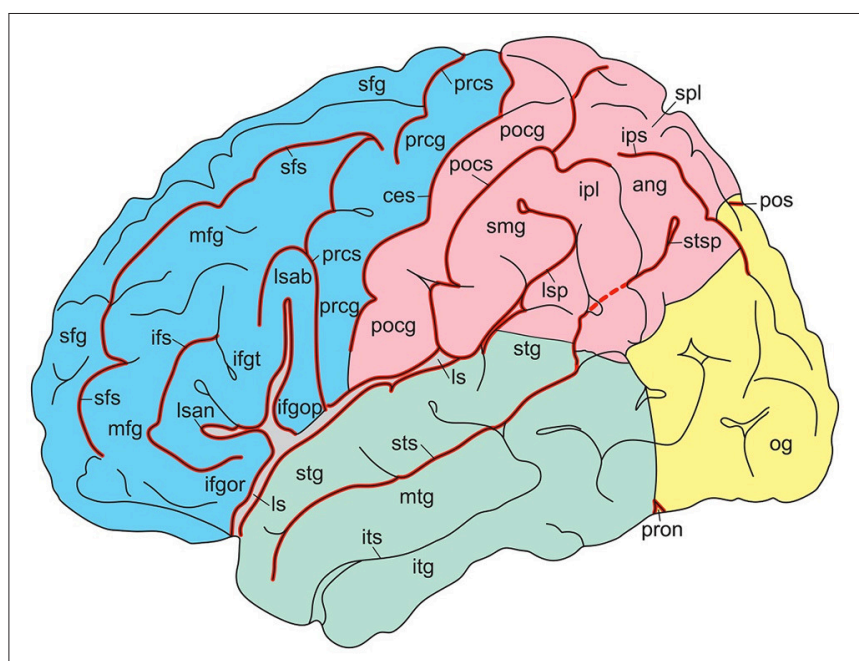

FIGURE 4 | Gyri and sulci of the lateral aspect of the standard brain (from Nieuwenhuys et al., 2015; with permission from Springer Nature). ang, angular gyrus; ces, central sulcus; ifgop, ifgor, ifgt, inferior frontal gyrus, orbital, opercular, and triangular parts; ifs, inferior frontal sulcus; ipl, inferior parietal lobule; ips, intraparietal sulcus; itg, inferior temporal gyrus; its, inferior temporal sulcus; Is, Isab, Isan, Isp, lateral sulcus with ascending, anterior, and posterior branches; $m f g$, middle temporal gyrus; $m t g$, middle temporal sulcus; og, occipital gyri; pocg, postcentral gyrus; pocs, postcentral sulcus; pos, parietooccipital sulcus; prcg, precentral gyrus; prcs, precentral sulcus; pron, preoccipital notch; sfg, superior frontal gyrus; sfs, superior frontal sulcus; smg, supramarginal gyrus; $s p l$, superior parietal lobule; stg, superior temporal gyrus; sts, stsp, superior temporal sulcus with posterior part.

The triangular insula of Reil lies in the depths of the lateral sulcus and is covered by the frontal, frontoparietal, parietal, and temporal opercula (Türe et al., 1999; Naidich et al., 2004; Morel 


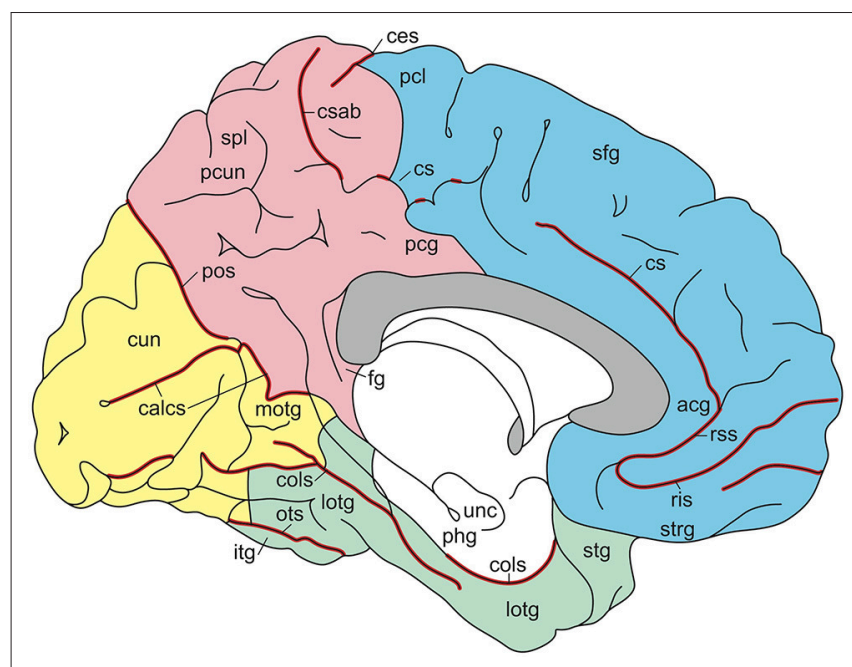

FIGURE 5 | Gyri and sulci of the medial aspect of the standard brain (from Nieuwenhuys et al., 2015; with permission from Springer Nature). acg, anterior cingulate gyrus; calcs, calcarine sulcus; ces, central sulcus; cols, collateral sulcus; cs, csab, cingulate sulcus with ascending branch; cun cuneus; fg, fasciolar gyrus; itg, inferior temporal gyrus; lotg, lateral occipitotemporal gyrus (fusiform gyrus); motg, medial occipitotemporal gyrus (lingual gyrus); ots, occipitotemporal sulcus; pcg, posterior cingulate gyrus; $p c l$, paracentral lobule; pcun, precuneus; phg, parahippocampal gyrus; pos, parietooccipital sulcus; ris, rss, rostral inferior and rostral superior sulcus; sfg, superior frontal gyrus; spl, superior parietal lobule; stg, superior temporal gyrus; strg, straight gyrus; unc, uncus.

et al., 2013; Figure 8). The limen insulae, the insular threshold or frontotemporal junction, forms the transition from the anterior perforated substance on the basal aspect of the frontal lobe to the insula. The insula is surrounded by the circular sulcus of the insula (sulcus circularis insulae of Reil) or periinsular sulcus, and contains several vertically directed gyri, usually three short gyri (gyri breves insulae), anterior, middle and posterior, and one or two long gyri (gyri longi insulae), anterior and posterior, separated by the central sulcus of the insula (sulcus centralis insulae) or transverse insular sulcus of Eberstaller. The three short gyri converge to the apex of the insula, and are joined to the orbital part of the inferior frontal gyrus by a short annectant gyrus, the transverse insular gyrus (gyrus transversus insulae of Eberstaller).

The lateral aspect of the parietal lobe (lobus parietalis) shows the postcentral gyrus (gyrus postcentralis), the postcentral sulcus (sulcus postcentralis), and the superior and inferior parietal lobules (lobulus parietalis superior and - inferior), numbered P1 and P2, respectively, and separated by the intraparietal sulcus (sulcus intraparietalis). Dorsally, the parietal lobe is connected with the occipital lobe by the parietooccipital arc (arcus parietooccipitalis) of Gratiolet. Another "pli de passage" connects the posterior part of the angular gyrus with the superior occipital gyrus. In monkeys, the intraparietal sulcus contains numerous intraparietal areas (AIP, LIP, MIP, PIP, and VIP; Rizzolatti et al., 1998; ten Donkelaar, 2011; Zilles and Amunts, 2012). In an fMRI study, Seitz and Binkofski (2003) identified AIP and VIP in the human brain. Two cytoarchitectonic areas were identified and termed hIP (human IntraParietal) 1 and hIP2 in the anterior part of the intraparietal sulcus (Choi et al., 2006), which may be the anatomical correlates of VIP and AIP, respectively (see also Zlatkina and Petrides, 2014). A third intraparietal area, hIP3, was delineated in the anterior medial wall of the intraparietal sulcus, directly across hIP1 and hIP2 (Scheperjans et al., 2008a,b).

The inferior parietal lobule (IPL) consists of the supramarginal and angular gyri (gyrus supramarginalis and - angularis), both of which can be further subdivided (see Caspers et al., 2012). The supramarginal gyrus surrounds the posterior ascending ramus of the lateral sulcus and can be subdivided into five areas. The angular gyrus lies around the caudal end of the superior temporal gyrus and is composed of two areas. The first intermediate sulcus (sulcus intermedius primus of Jensen) may subdivide the inferior parietal lobule into the supramarginal and angular gyri, and the second intermediate sulcus (sulcus intermedius secundus of Eberstaller) may be found posterior to the Jensen sulcus, dividing the angular gyrus into anterior and posterior parts.

The transverse parietal sulcus (sulcus parietalis transversus of Brissaud) may subdivide the superior parietal lobule (SPL) into anterior and posterior portions, when it extends on the superolateral aspect of the cerebrum. The SPL includes the preparietal area, the superior parietal area, each with subdivisions (see Scheperjans et al., 2008a,b). The parietal operculum (operculum parietale) contains four cytoarchitectonic areas (OP1-OP4), corresponding to the secondary somatosensory cortex (Eickhoff et al., 2006a,b).

Most of the occipital lobe (lobus occipitalis) is found on the medial aspect of the cerebrum. An imaginary line between the parietooccipital sulcus superiorly and the preoccipital notch inferiorly indicates the border between the occipital lobe and the parietal and temporal lobes. On the superolateral aspect, the following occipital gyri and sulci can be found: the superior occipital gyrus (O1 or gyrus occipitalis superior), the middle occipital gyrus (O2 or gyrus occipitalis medius), the upper and lower parts of which are separated by the lunate sulcus (sulcus lunatus), the inferior occipital gyrus (O3 or gyrus occipitalis inferior) and the descending occipital gyrus (gyrus occipitalis descendens of Ecker). An inferior occipital sulcus (sulcus occipitalis inferior) may divide the lower part of $\mathrm{O} 2$ from $\mathrm{O} 3$. For variations of the gyri and sulci on the occipital lobe convexity, see Ono et al. (1990), Alves et al. (2012) and Malikovic et al. (2012).

\section{INFEROMEDIAL SURFACE OF THE CEREBRAL HEMISPHERE}

On the inferomedial surface of the cerebral hemisphere, interlobar sulci include the continuation of the central sulcus, the cingulate sulcus, the sulcus of the corpus callosum, the parietoccipital sulcus, the subparietal sulcus and the collateral sulcus (Figure 9; and Table 2). The cingulate sulcus (sulcus cinguli or "scissure limbique" of Broca, 1878b) runs parallel to the corpus callosum and ascends above the posterior part (the splenium) of the corpus callosum toward the superior 
TABLE 1 | Sulci and on the superolateral surface of the cerebral hemisphere (based on TNA, 2017; ten Donkelaar et al., 2018).

\begin{tabular}{|c|c|c|c|}
\hline English official terms and synonyms & Latin official terms and synonyms & Abbreviations and acronyms & Eponyms \\
\hline Superolateral interlobar sulci & Sulci interlobares superolaterales & & \\
\hline central sulcus & sulcus centralis & ces & sulcus of Rolando \\
\hline posterior ramus & ramus posterior & Isp & \\
\hline ascending ramus & ramus ascendens & Isas & \\
\hline preoccipital notch & incisura preoccipitalis & pn & incisure of Meynert \\
\hline Frontal lobe & Lobus frontalis & & \\
\hline frontomarginal sulcus & sulcus frontomarginalis & fmgs & sulcus of Wernicke \\
\hline frontal pole & polus frontalis & $\mathrm{FP}$ & \\
\hline frontopolar area & area frontopolaris & FPA & \\
\hline frontal operculum & operculum frontale & FOp & \\
\hline inferior frontal gyrus & gyrus frontalis inferior & IFG; F3 & \\
\hline orbital part & pars orbitalis & IFGOr & \\
\hline triangular part & pars triangularis & IFGTr & area of Broca \\
\hline radiate sulcus & sulcus radiatus & ras & sulcus of Eberstaller \\
\hline opercular part & pars opercularis & IFGOp & area of Broca \\
\hline diagonal sulcus & sulcus diagonalis & dis & sulcus of Eberstaller \\
\hline inferior frontal sulcus & sulcus frontalis inferior & ifs; f2 & \\
\hline middle frontal gyrus & gyrus frontalis medius & MFG; F2 & \\
\hline precentral gyrus & gyrus precentralis & PRG & \\
\hline Parietal lobe & Lobus parietalis & & \\
\hline postcentral gyrus & gyrus postcentralis & POG & \\
\hline postcentral sulcus & sulcus postcentralis & pcs & \\
\hline superior parietal lobule & lobulus parietalis superior & SPL; P1 & \\
\hline parietooccipital arc & arcus parietooccipitalis & POcA & $\begin{array}{l}\text { first parietooccipital } \\
\text { passage of Gratiolet }\end{array}$ \\
\hline intraparietal sulcus & sulcus intraparietalis & ips & \\
\hline $\begin{array}{l}\text { first intermediate sulcus; anterior } \\
\text { intermediate sulcus }\end{array}$ & $\begin{array}{l}\text { sulcus intermedius primus; sulcus } \\
\text { intermedius anterior }\end{array}$ & fis & sulcus of Jensen \\
\hline $\begin{array}{l}\text { second intermediate sulcus; posterior } \\
\text { intermediate sulcus }\end{array}$ & $\begin{array}{l}\text { sulcus intermedius secundus; sulcus } \\
\text { intermedius posterior }\end{array}$ & sis & sulcus of Eberstaller \\
\hline transverse parietal sulcus & sulcus parietalis transversus & tps & sulcus of Brissaud \\
\hline inferior parietal lobule & lobulus parietalis inferior & IPL; P2 & \\
\hline angular gyrus & gyrus angularis & $A G$ & \\
\hline parietal operculum & operculum parietale & POp & \\
\hline supramarginal gyrus & gyrus supramarginalis & SMG & \\
\hline
\end{tabular}


TABLE 1 | Continued

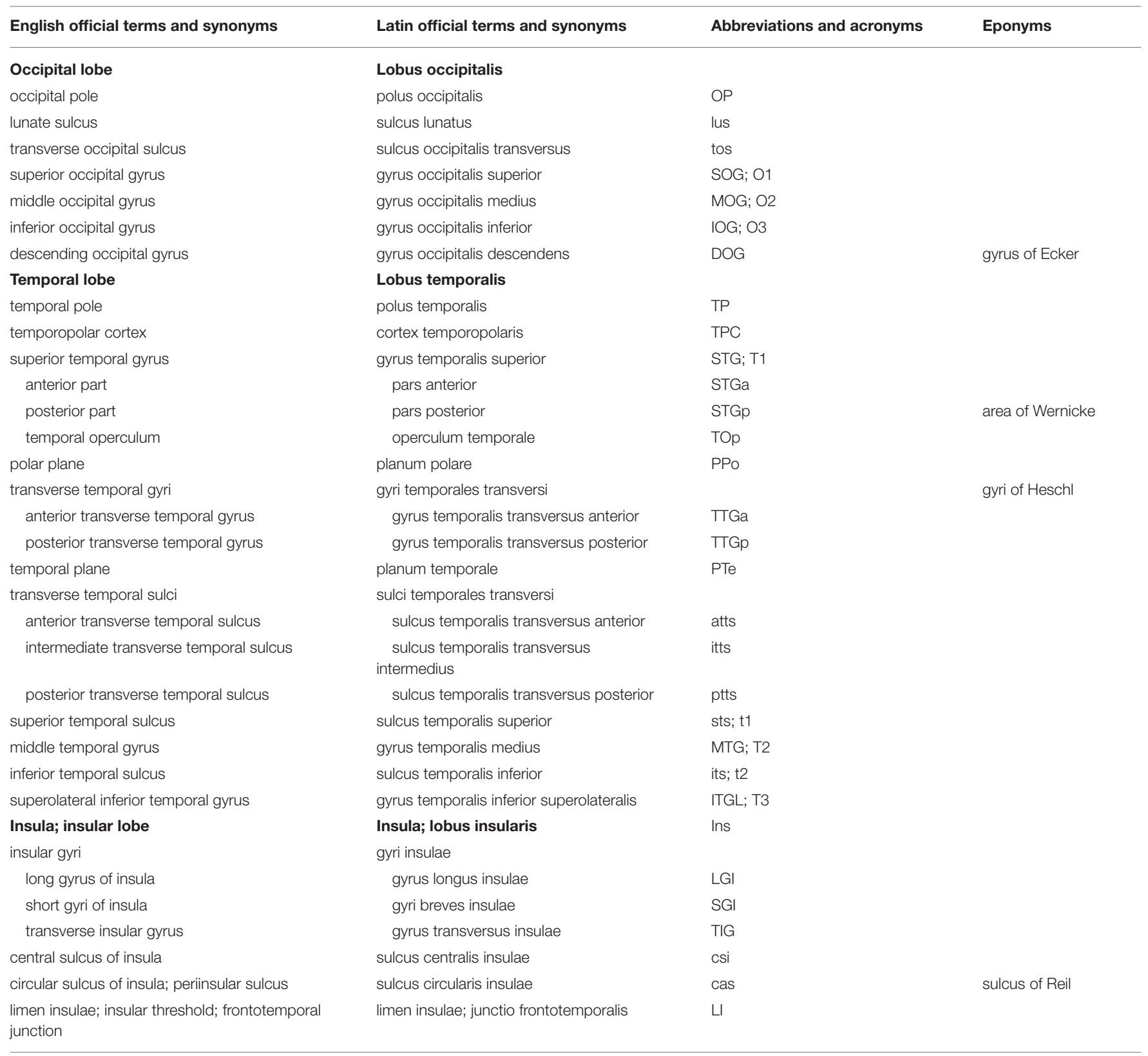

For a summarizing figure, see Figure 6.

margin of the hemisphere. It gives off a marginal branch or sulcus (ramus marginalis or sulcus marginalis). The cingulate sulcus continues around the rostrum of the corpus callosum, where it is also known as the superior rostral sulcus (sulcus rostralis superior). This sulcus may continue as the inferior rostral sulcus (sulcus rostralis inferior), which separates the straight gyrus from the medial surface of the frontal lobe (see Figure 5). Immediately rostral to the ascending part of the cingulate sulcus courses the medial end of the central sulcus. The cingulate sulcus divides the medial aspect of the cerebral cortex into an outer and an inner zone. The outer zone is composed of the medial part of the superior frontal gyrus (F1 or gyrus frontalis superior) and the paracentral lobule (lobulus paracentralis), which surrounds the medial end of the central sulcus, and has frontal and parietal components. Frequently, a series of furrows delineates the paracingulate sulcus (sulcus paracinguli), which separates the medial division of the superior frontal gyrus from the paracingulate gyrus (gyrus paracinguli; see Figure 2B), also known as the external cingulate gyrus (Ono et al., 1990). This gyrus is separated ventrally by the cingulate sulcus from the cingulate gyrus (Ono et al., 1990; Paus et al., 1996; Ide et al., 1999). Such a double-parallel pattern, where the paracingulate sulcus surrounds the cingulate sulcus, was found in $24 \%$ of either hemisphere in Ono's cases. Ide et al. 


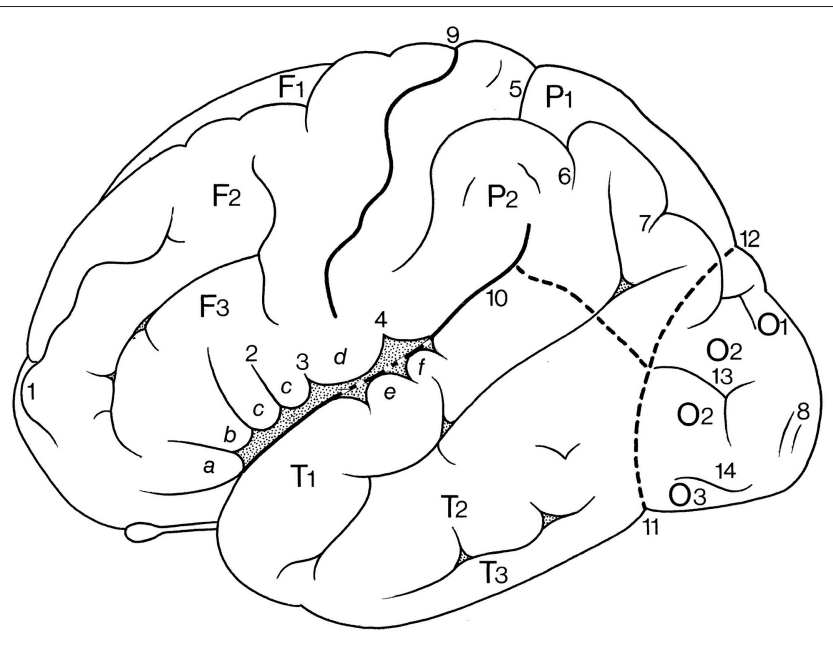

FIGURE 6 | Gyri and sulci on the superolateral surface of the cerebral hemisphere (after Duvernoy, 1992; ten Donkelaar et al., 2018). a, b, c, orbital, triangular, and opercular (divided into two parts by 2) parts of the inferior frontal gyrus; $d$, subcentral gyrus; e, f, transverse temporal gyri of Heschl; F1, F2, F3, superior, middle, and inferior frontal gyri; $01,02,03$, superior, middle, and inferior occipital gyri; $P 1, P 2$, superior and inferior parietal lobules; T1, T2, T3, superior, middle, and inferior temporal gyri; 1 , frontomarginal sulcus of Wernicke; 2, diagonal sulcus of Eberstaller; 3, anterior subcentral sulcus; 4, posterior subcentral sulcus; 5, transverse parietal sulcus of Brissaud; 6, first intermediate sulcus of Jensen; 7, second intermediate sulcus of Eberstaller; 8, descending occipital gyrus of Ecker; 9, central sulcus; 10, lateral sulcus; 11, preoccipital notch of Meynert; 12, parietooccipital sulcus; 13, lunate sulcus; 14 , inferior occipital sulcus.

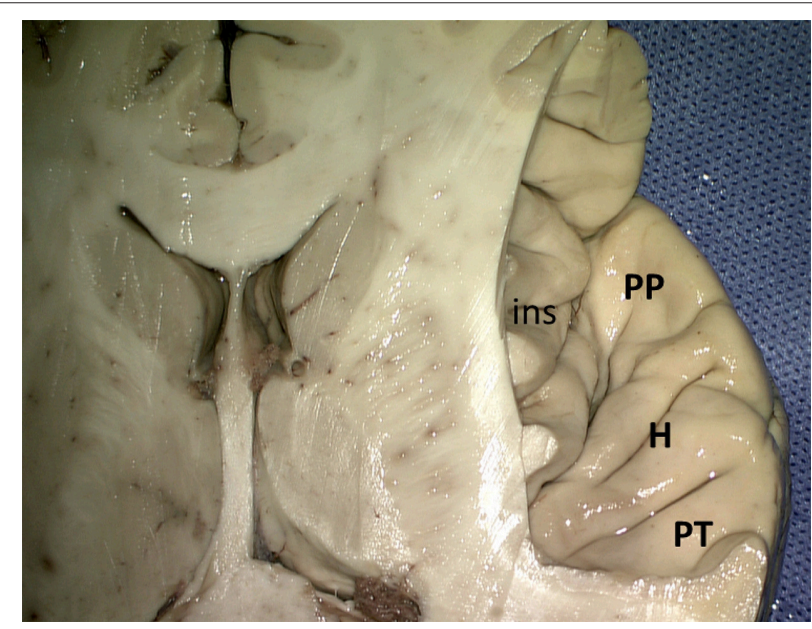

FIGURE 7 | Superior view of the right superior temporal sulcus (kindly provided by Robert Bartoš, Ústí nad Labem, Czech Republic). ins, insula; $H$, Heschl gyri; PP, planum polare; $P T$, planum temporale.

(1999) found a single sulcus more frequently on the right (69\%) than on the left (31\%) hemispheres, whereas the double pattern was more frequent on the left $(68 \%)$ than right $(32 \%)$ hemispheres.

Caudal to the paracentral lobule lies the large precuneus (P1), bordered by the marginal branch of the cingulate

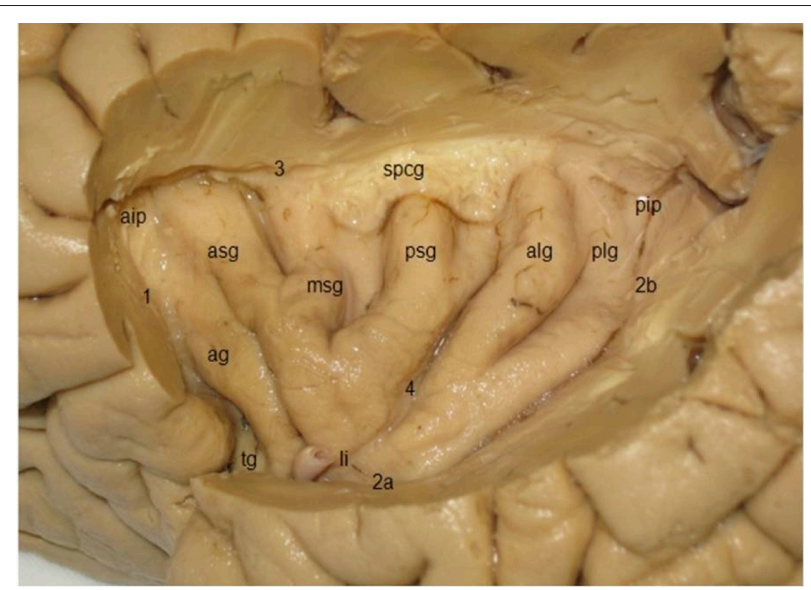

FIGURE 8 | Lateral view of the insula, showing three short gyri, an accessory gyrus and two long gyri (kindly provided by Robert Bartoš, Ústí nad Labem, Czech Republic). ag, accessory gyrus; aip, anterior insular point; alg, anterior long gyrus; asg, anterior short gyrus, li limen insulae; msg, middle short gyrus; pip, posterior insular point; plg, posterior long gyrus; psg, posterior short gyrus; spcg, gyrus supracentralis; tg, transverse insular gyrus; 1-3, circular insular sulcus (1 anterior periinsular sulcus, 2a, 2b, inferior insular sulcus, horizontal, and posterior parts; 3 , superior periinsular sulcus); 4, central insular sulcus.

sulcus (ramus marginalis sulci cinguli) rostrally, the parietooccipital sulcus (sulcus parietooccipitalis of Gratiolet) caudally, and the subparietal sulcus (sulcus subparietalis) ventrally.

The inner zone, separated from the corpus callosum by the sulcus of the corpus callosum (sulcus corporis callosi), and earlier known as the fornicate gyrus (gyrus fornicatus of Meynert), is formed by the cingulate gyrus (gyrus cinguli). The cingulate gyrus can be divided into four parts: an anterior part, a midcingulate cortex, a posterior part and a retrosplenial part (Vogt and Palomero-Gallagher, 2012). The cingulate gyrus is continuous through a narrowing (isthmus gyri cinguli) with the parahippocampal gyrus (gyrus parahippocampalis or T5) in the temporal lobe. The collateral sulcus (sulcus collateralis, also known as the medial occipitotemporal sulcus) separates T5 from T4, the temporal part of the fusiform gyrus (gyrus fusiformis, also known as the lateral occipitotemporal gyrus). Areas of the fusiform gyrus within the inferotemporal cortex are part of the ventral visual stream area (see Rosenke et al., 2018), and they process higher-order visual information associated with faces, limbs, words, and places. Caspers et al. (2013) identified two areas, FG1 and FG2, medial and lateral in the posterior part of the fusiform gyrus, respectively. Lorenz et al. (2017) identified two new areas, FG3 and FG4, medial and lateral in the midfusiform gyrus, respectively, separated by the midfusiform sulcus (sulcus fusiformis medius). The occipitotemporal sulcus (sulcus occipitotemporalis, also known as the lateral occipitotemporal sulcus) separates the medial part of the inferior temporal gyrus (T3 or gyrus temporalis inferior) from T4. Various classifications for the temporal sulci and gyri have been published (Ono et al., 1990; Duvernoy, 1992; Hanke, 1997; 
TABLE 2 | Sulci and gyri on the inferomedial surface of the cerebral hemisphere (based on TNA, 2017; ten Donkelaar et al., 2018).

\begin{tabular}{|c|c|c|c|}
\hline English official terms and synonyms & Latin official terms and synonyms & Abbreviations and acronyms & Eponyms \\
\hline Inferomedial interlobar sulci & Sulci Interlobares inferomediales & & \\
\hline sulcus of corpus callosum & sulcus corporis callosi & scc & \\
\hline marginal branch; marginal sulcus & ramus marginalis; sulcus marginalis & cgsmb & \\
\hline parietooccipital sulcus & sulcus parietooccipitalis & pos & sulcus of Gratiolet \\
\hline central sulcus & sulcus centralis & ces & \\
\hline Frontal lobe & Lobus frontalis & & \\
\hline inferomedial superior frontal gyrus & gyrus frontalis superior inferomedialis & SFGM; F1 & \\
\hline paracingulate sulcus & sulcus paracinguli & pcgs & \\
\hline paracingulate gyrus & gyrus paracinguli & PCG & \\
\hline subcallosal area; subcallosal gyrus & area subcallosa; gyrus subcallosus & SCA & \\
\hline paraterminal gyrus & gyrus paraterminalis & PTG & \\
\hline paraolfactory area & area paraolfactoria & $\mathrm{PaOA}$ & \\
\hline paraolfactory gyrus & gyrus paraolfactorius & $\mathrm{PaOG}$ & \\
\hline paraolfactory sulci & sulci paraolfactorii & & \\
\hline anterior paraolfactory sulcus & sulcus paraolfactorius anterius & apaos & \\
\hline posterior paraolfactory sulcus & sulcus paraolfactorius posterius & ppaos & \\
\hline orbital gyri & gyri orbitales & & \\
\hline medial orbital gyrus & gyrus orbitalis medialis & MOrG & \\
\hline anterior orbital gyrus & gyrus orbitalis anterior & AOrG & \\
\hline posterior orbital gyrus & gyrus orbitalis posterior & POrG & \\
\hline superior rostral sulcus & sulcus rostralis superior & srs & \\
\hline inferior rostral sulcus & sulcus rostralis inferior & irs & \\
\hline straight gyrus & gyrus rectus & $S G$ & \\
\hline olfactory sulcus & sulcus olfactorius & ols & \\
\hline $\begin{array}{l}\text { anterior perforated substance; rostral } \\
\text { perforated substance }\end{array}$ & $\begin{array}{l}\text { substantia perforata anterior; substantia } \\
\text { perforata rostralis }\end{array}$ & APS & \\
\hline Olfactory structures & Structurae olfactoriae & & \\
\hline olfactory bulb & bulbus olfactorius & OB & \\
\hline olfactory peduncle & pedunculus olfactorius & op & \\
\hline olfactory tract & tractus olfactorius & ot & \\
\hline olfactory trigone & trigonum olfactorium & OT & \\
\hline olfactory tubercle & tuberculum olfactorium & Tu & \\
\hline olfactory striae & striae olfactoriae & & \\
\hline medial olfactory stria & stria olfactoria medialis & mos & \\
\hline lateral olfactory stria & stria olfactoria lateralis & los & \\
\hline retrobulbar region & regio retrobulbaris & RBR & \\
\hline piriform cortex & $\begin{array}{l}\text { cortex piriformis; cortex olfactorius } \\
\text { primarius }\end{array}$ & Pir & \\
\hline
\end{tabular}


TABLE 2 | Continued

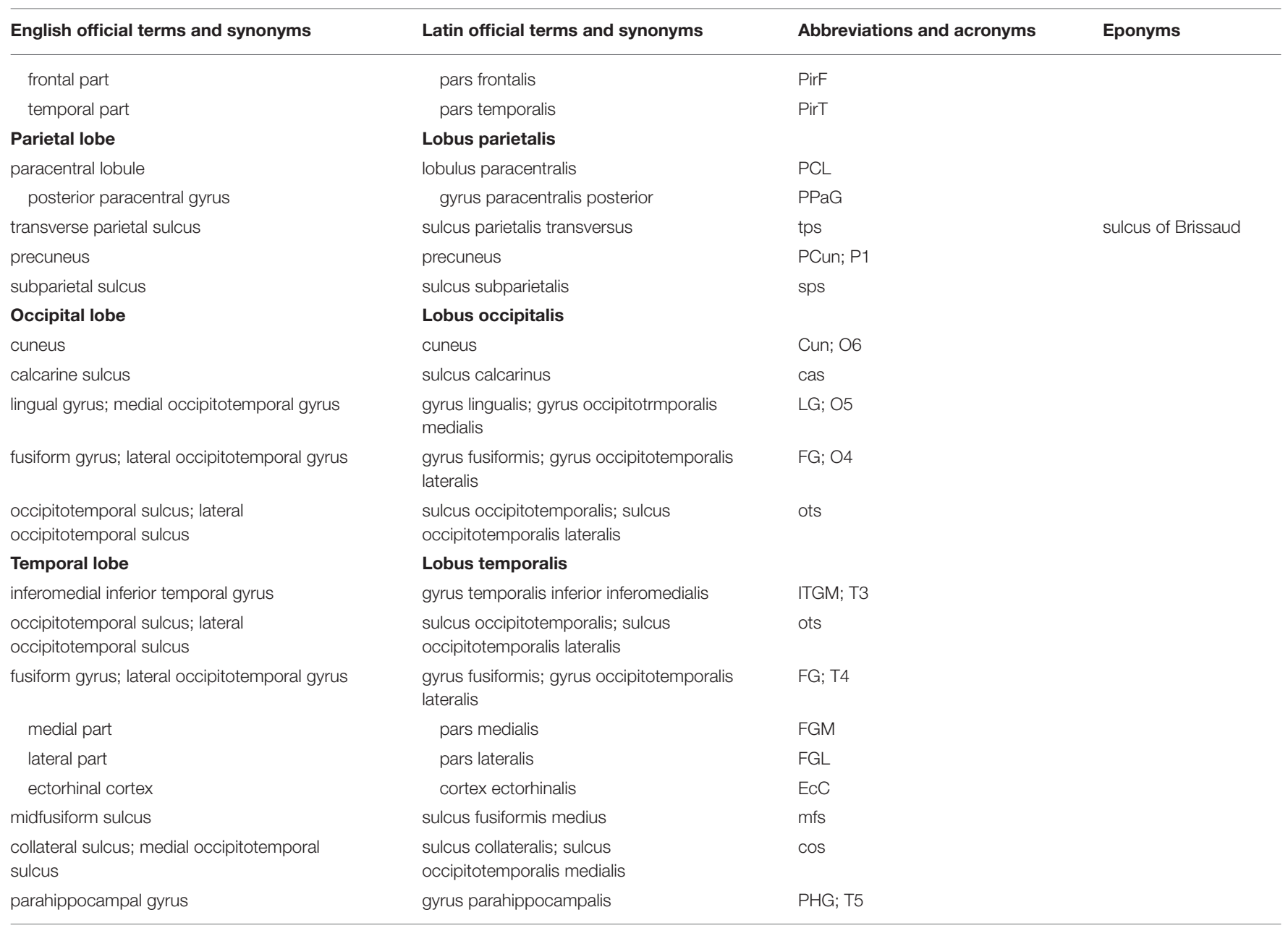

For summarizing figures, see Figures 9, 10.

Huntgeburth and Petrides, 2012; Chau et al., 2014; Cikla et al., 2016) with different relations between the collateral and rhinal sulci and patterns of the various sulci.

The posterior part of the medial cerebral cortex has two deep sulci, which converge toward the splenium. The interlobar parietooccipital sulcus (sulcus parietooccipitalis of Gratiolet) separates the parietal and occipital lobes, and the lobar calcarine sulcus (sulcus calcarinus) divides the occipital lobe into a dorsal part, the cuneus (O6) and a ventral part, the lingual or medial occipitotemporal gyrus (O5; gyrus lingualis or gyrus occipitotemporalis medialis). The lingual gyrus may be divided into two parts by the lingual sulcus (sulcus lingualis). The primary visual cortex is mainly found on both sides of the calcarine sulcus. Below the lingual gyrus, separated by the occipitotemporal sulcus (sulcus occipitotemporalis), lies the occipital part of the fusiform or lateral occipitotemporal gyrus (O4; gyrus fusiformis or gyrus occipitotemporalis lateralis). The visual areas outside the striate area (area striata) are grouped together as the extrastriate areas (areae extrastriatae; for current views and further discussion, see Wang et al., 2015).

\section{BASAL SURFACE OF THE CEREBRAL HEMISPHERE}

On the basal surface of the cerebral hemisphere, the occipital lobes are largely covered by the cerebellum, so only the frontal and temporal lobes are visible (Figure 10; and Table 2). On the orbital surface of the frontal lobe, the olfactory sulcus (sulcus olfactorius) with the olfactory bulb and tract separates the straight gyrus (gyrus rectus) from the orbital gyri. The olfactory tract divides into the medial and lateral olfactory striae, of which only the lateral olfactory tract contains secondary olfactory fibers. Between these striae lies the anterior perforated substance of Vicq d'Azyr, a region studded with small openings through which the anteromedial central arteries and the recurrent artery of Heubner from the anterior cerebral artery and the lenticulostriate arteries from the middle cerebral artery pass to the basal ganglia and the internal capsule. The medial part of the temporal lobe is formed by the parahippocampal gyrus (T5; gyrus parahippocampalis or medial occipitotemporal gyrus), the continuation of the cingulate gyrus. The most rostral part of the 


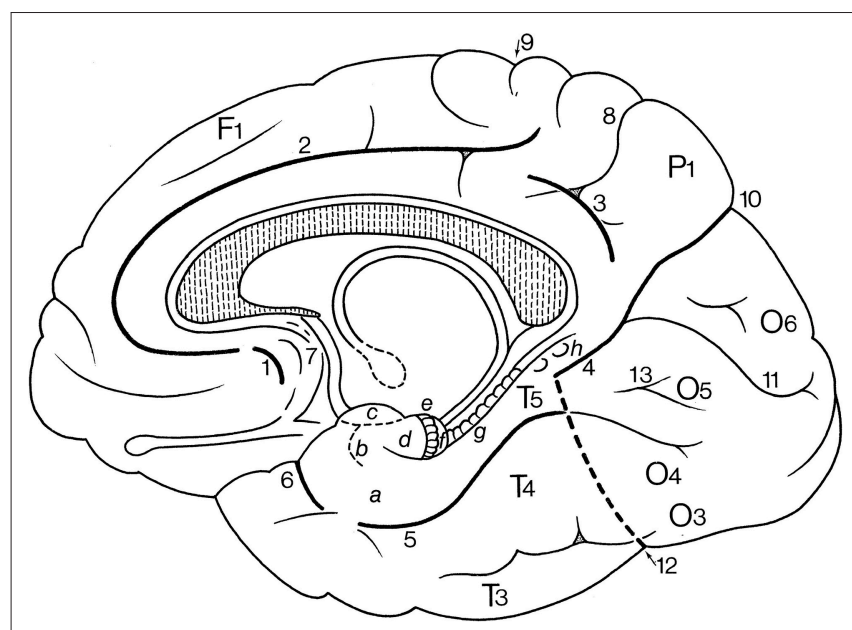

FIGURE 9 | Gyri and sulci on the inferomedial surface of the cerebral hemisphere (after Duvernoy, 1992; ten Donkelaar et al., 2018). (1) below F1, the paracingulate sulcus; and (2) below the subcallosal part of 2, the rostral sulcus. $a$, entorhinal cortex; $b$, ambient gyrus; $c$, semilunar gyrus; $d$, uncinate gyrus; $e$, band of the dentate gyrus of Giacomini; $f$, intralimbic gyrus or uncal apex; g, dentate gyrus; $h$, gyri of Andreas Retzius or subsplenial gyri; F1, superior frontal gyrus; $P 1$, precuneus; $O 3$, inferior occipital gyrus; $\mathrm{O}$, fusiform gyrus (occipital part); O5, lingual gyrus; O6, cuneus; T3, inferior temporal gyrus; T4, fusiform gyrus (temporal part); T5, parahippocampal gyrus; 1-6, parts of the "limbic sulcus" or "scissure limbique": 1, anterior paraolfactory sulcus; 2, cingulate sulcus; 3 , subparietal sulcus; 4 , anterior part of parietooccipital sulcus; 5, collateral sulcus; 6, rhinal sulcus; 7, posterior paraolfactory sulcus; 8 , transverse parietal sulcus of Brissaud; 9 , central sulcus; 10 , parietooccipital sulcus; 11 , calcarine sulcus; 12, preoccipital notch of Meynert; 13, lingual sulcus.

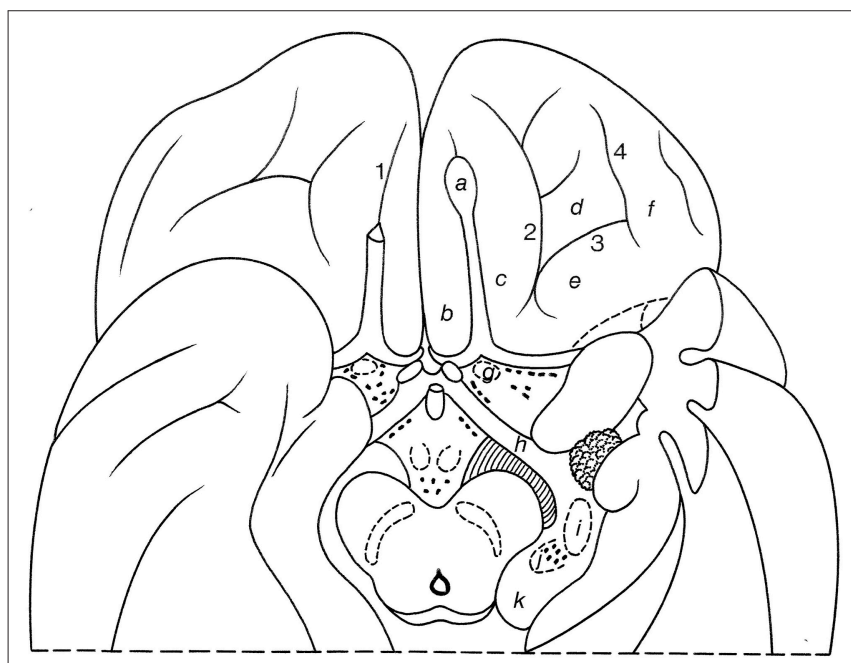

FIGURE 10 | Gyri and sulci on the orbital part of the frontal lobe, shown for the basal surface of the cerebral hemisphere (after Duvernoy, 1992; ten Donkelaar et al., 2018). a, olfactory bulb; $b$, straight gyrus; $c, d$, e, $f$, medial, anterior, posterior, and lateral olfactory gyri; $g$, olfactory tubercle; $h$, optic tract; $i$, lateral geniculate body; $j$, medial geniculate body; $k$, pulvinar; 1 , olfactory sulcus; 2 , medial orbital sulcus; 3 , transverse orbital sulcus; 4 , lateral orbital sulcus.

parahippocampal gyrus protrudes medially as the uncus. Below the uncus lies the amygdala. Lateral to the parahippocampal gyrus, the following structures can successively be observed: the collateral sulcus (sulcus collateralis), the fusiform gyrus (T4; gyrus fusiformis) or lateral occipitotemporal gyrus, the occipitotemporal sulcus (sulcus occipitotemporalis), and the inferior temporal gyrus (T3; gyrus temporalis inferior).

The naming of two "olfactory gyri" in the TA (1998) suggested that there were clearly identifiable gyral structures; this is not true. These terms persisted from the old description of the "rhinencephalon" (see Gastaut and Lammers, 1961; Stephan, 1975) and have been deleted in the TNA (2017). The real olfactory cortex is the piriform or primary olfactory cortex (cortex piriformis or cortex olfactorius primarius), which can be divided into frontal and temporal parts (Allison, 1954; Heimer et al., 1977, 1999; Zilles, 2004; Zilles and Amunts, 2012; ten Donkelaar et al., 2018).

In the TNA (2017), the TA names for the sulci and gyri in the orbitofrontal cortex have been corrected. Lateral to the olfactory sulcus, there are two longitudinally directed sulci, the medial orbital sulcus (sulcus orbitalis medialis) and the lateral orbital sulcus (sulcus orbitalis lateralis), which are joined by the transverse orbital sulcus (sulcus orbitalis transversus) to form an $\mathrm{H}$ or a K pattern (Duvernoy, 1992; Chiavaras and Petrides, 2000; Öngur et al., 2003; Petrides and Pandya, 2012; Rolls et al., 2015; ten Donkelaar et al., 2018). The following orbital gyri can be found: the medial orbital gyrus (gyrus orbitalis medialis) between the olfactory sulcus and the medial orbital sulcus, the anterior orbital gyrus (gyrus orbitalis anterior), the cortex rostral to the transverse orbital sulcus, the posterior orbital gyrus (gyrus orbitalis posterior), the cortex caudal to the transverse orbital sulcus, and the lateral orbital gyrus (gyrus orbitalis lateralis) lateral to the lateral orbital sulcus. The caudal parts of the medial and posterior orbital gyri merge to form the posteromedial orbital lobule (lobulus orbitalis posteromedialis) as described by Türe et al. (1999) and Naidich et al. (2004). The posteromedial orbital lobule gives rise to the transverse insular gyrus (gyrus transversus insulae). Mai and Majtanik (2017) also distinguished a posterolateral orbital region (regio orbitalis posterolateralis) between the posterior orbital gyrus and the orbital part of the inferior frontal gyrus.

\section{THE LIMBIC LOBE}

The cingulate gyrus and the parahippocampal gyrus form a border (limbus) around the corpus callosum and the brain stem (Broca, 1878b). Broca subdivided his grand lobe limbique into inner (the hippocampal formation) and outer (the cingulate and parahippocampal) rings for which now the general descriptive term limbic lobe is used (Heimer et al., 2008; Nieuwenhuys et al., 2008). The "scissure limbique" separates the limbic lobe from the rest of the cerebral cortex and can be seen as an interlobar sulcus (Duvernoy, 1992; ten Donkelaar et al., 2018). It consists of (Figure 11; and Table 3): the anterior paraolfactory sulcus (sulcus paraolfactorius anterior) in the subcallosal area, the cingulate sulcus (sulcus cinguli), part of the subparietal sulcus, the rostral part of the parietooccipital sulcus, the collateral sulcus (sulcus collateralis), and the rhinal sulcus (sulcus rhinalis).

The limbic lobe consists of an inner ring (known as the intralimbic gyrus in the French literature; Testut and Latarjet, 
TABLE 3 | Structures of the limbic lobe (based on TNA, 2017; ten Donkelaar et al., 2018).

\begin{tabular}{|c|c|c|c|}
\hline English official terms and synonyms & Latin official terms and synonyms & Abbreviations and acronyms & Eponyms \\
\hline Limbic gyrus; outer ring of limbic lobe & Gyrus limbicus & & \\
\hline subcallosal area; subcallosal gyrus & area subcallosa; gyrus subcallosus & SCA & \\
\hline cingulate gyrus & gyrus cinguli & CG & \\
\hline anterior cingulate cortex & gyrus cinguli, pars anterior & ACC & \\
\hline midcingulate cortex & gyrus cinguli, pars media & MCC & \\
\hline isthmus of cingulate gyrus & isthmus gyri cinguli & ICG & \\
\hline parahippocampal gyrus & gyrus parahippocampalis & PHG; T5 & \\
\hline entorhinal cortex & cortex entorhinalis & EC & \\
\hline white reticular substance & substantia reticularis alba & & substance of Arnold \\
\hline hippocampal warts & verrucae hippocampi & & \\
\hline semianular sulcus & sulcus semianularis & sas & \\
\hline semilunar gyrus & gyrus semilunaris & SLG & \\
\hline uncinate gyrus & gyrus uncinatus & UG & \\
\hline band of dentate gyrus & limbus fasciae dentatae & $\mathrm{BDG}$ & band of Giacomini \\
\hline intralimbic gyrus; uncal apex & gyrus intralimbicus & ILG & \\
\hline collateral sulcus & sulcus collateralis & $\cos$ & \\
\hline rhinal sulcus & sulcus rhinalis & rhs & \\
\hline intrarhinal sulcus & sulcus intrarhinalis & irhs & \\
\hline $\begin{array}{l}\text { Hippocampal formation; inner ring of } \\
\text { limbic lobe }\end{array}$ & Formatio hippocampi & & \\
\hline precommissural part of hippocampus & pars precommissuralis hippocampi & HiP & \\
\hline pes hippocampi; pes of hippocampus & pes hippocampi & PHip & \\
\hline head; anterior segment & caput; pars anterior & $\mathrm{HiH}$ & \\
\hline body; middle sement & corpus; pars media & $\mathrm{HiB}$ & \\
\hline tail; posterior segment & cauda; pars posterior & HiT & \\
\hline hippocampal sulcus & sulcus hippocampalis & his & \\
\hline dentate gyrus & gyrus dentatus & DG & \\
\hline fimbriodentate sulcus & sulcus fimbriodentatus & fds & \\
\hline fimbria of hippocampus & fimbria hippocampi & $\mathrm{FiH}$ & \\
\hline gyri of andreas retzius; subsplenial gyri & dentes subiculi; gyri subspleniales & GAR; SG & \\
\hline fasciolar gyrus & gyrus fasciolaris & $F G$ & \\
\hline fasciola cinerea & fasciola cinerea & $\mathrm{FC}$ & \\
\hline subiculum & subiculum & S & \\
\hline presubiculum & presubiculum & PrS & \\
\hline parasubiculum & parasubiculum & Pas & \\
\hline
\end{tabular}

For summarizing figures, see Figures 9, 11. 


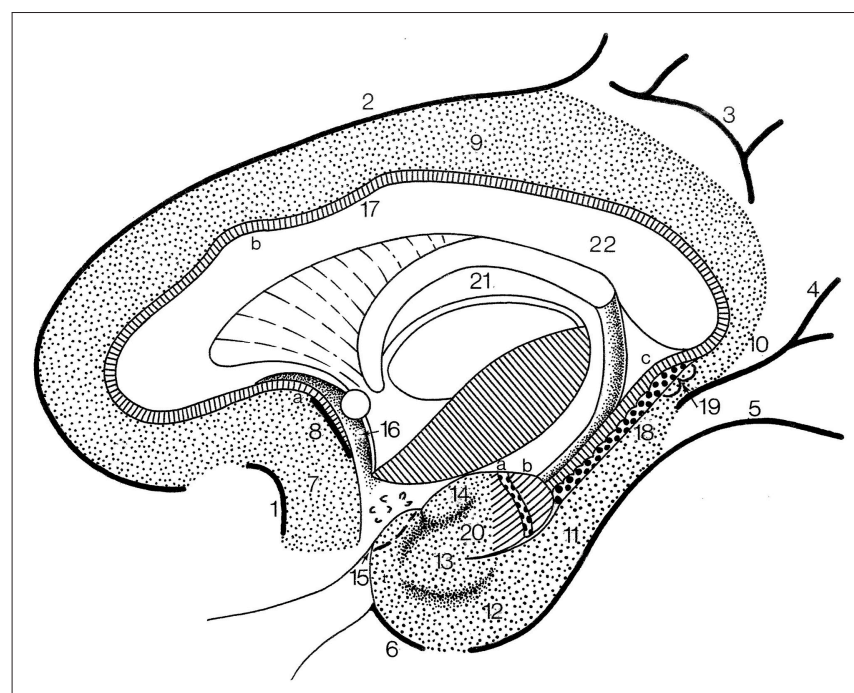

FIGURE 11 | The limbic lobe (after Duvernoy, 1998; ten Donkelaar et al., 2018). 1, anterior paraolfactory sulcus; 2 , cingulate sulcus; 3 , subparietal sulcus; 4, rostral part of calcarine sulcus; 5, collateral sulcus; 6, rhinal sulcus; 7, subcallosal gyrus; 8, posterior paraolfactory sulcus; 9, cingulate gyrus; 10 , isthmus; 11, parahippocampal gyrus; 12, entorhinal cortex; 13, ambient gyrus; 14, semilunar gyrus; 15 , piriform cortex; 16, paraterminal gyrus; 17 , indusium griseum; 18, dentate gyrus; 19, gyri of Andreas Retzius; 20, uncinate gyrus; 21, fornix; 22, corpus callosum; $a$, bandelette of Giacomini; $b$, apex of uncus.

1948), the hippocampal formation (see below), and an outer ring, the limbic gyrus. The limbic gyrus (gyrus limbicus) includes: (1) the subcallosal area (area subcallosa or gyrus subcallosus), which includes the paraolfactory gyrus (gyrus paraolfactorius) between the anterior and posterior paraolfactory sulci, and the paraterminal gyrus (gyrus paraterminalis) just rostral to the lamina terminalis; (2) the cingulate gyrus (gyrus cinguli); (3) the isthmus of the cingulate gyrus (isthmus gyri cinguli); (4) the parahippocampal gyrus (gyrus parahippocampalis); (5) the entorhinal cortex (cortex entorhinalis); and (6) the uncus. In the TNA (2017), the uncus is treated as a structure separate from the parahippocampal gyrus, following Insausti and Amaral (2012). The entorhinal cortex (cortex entorhinalis; Braak and Braak, 1992; Insausti et al., 1995, 2017) is located at the rostral part of the parahippocampal gyrus, which includes the uncus (uncus) and small gyri called the the uncinate gyrus (gyrus uncinatus), the ambient gyrus (gyrus ambiens) and the semilunar gyrus (gyrus semilunaris). The entorhinal cortex corresponds to BA28 and has been subdivided into eight different subfields (Insausti et al., 1995). Adjacent is the perirhinal (Anglo-Saxon terminology) or transentorhinal (German terminology) cortex. The entorhinal cortex can be defined macroscopically by the white reticular matter (substantia reticularis alba of Arnold) and the hippocampal warts (verrucae hippocampi) described by Retzius (1896) and Klingler (1948). The entorhinal cortex is characterized by a dissecting layer (lamina dissecans), separating the external and internal layers, for which Rose (1926) introduced the term schizocortex.

The uncus (uncus) includes a number of bulges: (1) the uncinate gyrus (gyrus uncinatus), its most rostral part, corresponding to the amygdalohippocampal transition area (area transitionis amygdalohippocampalis); (2) the band of the dentate gyrus (limbus fasciae dentatae of Giacomini), the middle part, corresponding to the dentate gyrus; and (3) the intralimbic gyrus or uncal apex (gyrus intralimbicus), the most caudal part of the uncal bulge and corresponding to the CA3 field. The dorsal limit of the uncus is rather inconspicuous, but its ventral limit is marked by the hippocampal sulcus (sulcus hippocampalis). The hippocampal sulcus continues rostralwards as the intrarhinal sulcus (sulcus intrarhinalis), forming the ventral limit of the ambient gyrus (gyrus ambiens). The semianular sulcus (sulcus semianularis) separates the ambient gyrus from the semilunar gyrus (gyrus semilunaris), which forms the periamygdaloid cortex.

The perirhinal cortex (cortex perirhinalis) is a periarchicortical structure (Suzuki and Amaral, 1994; Augustinack et al., 2013) around the perirhinal sulcus (sulcus perirhinalis) and corresponds to the transentorhinal region (regio transentorhinalis) of Braak and Braak (1992). Its laminar structure is comparable to that of the entorhinal cortex. Adjacent to the perirhinal cortex is the ectorhinal cortex (cortex ectorhinalis), an isocortical part of the inferior temporal surface, but sometimes included in the perirhinal cortex (Ding and Van Hoesen, 2010).

Classically, the hippocampal formation (formatio hippocampi) is divided into three, originally adjacent, allocortical areas (Stephan, 1975; Duvernoy, 1998; ten Donkelaar, 2011): (1) the dentate gyrus (gyrus dentatus); (2) the hippocampus proper or Ammon's horn (hippocampus proprius or cornu ammonis); and (3) the subiculum (subiculum). These three structures are known as the archicortex. A small indentation between the fimbria and the molecular layer of the dentate gyrus has been termed the fimbriodentate sulcus (sulcus fimbriodentatus) by Gastaut and Lammers (1961). Several periallocortical structures, including the entorhinal cortex, the presubiculum and the parasubiculum, all parts of the parahippocampal gyrus, have also been included within the term "hippocampal formation," since they are closely related and share a common pattern of projections (Insausti and Amaral, 2012). The TNA (2017), however, follows the classic view.

The hippocampal formation develops from the medial pallium, and during the outgrowth of the cerebral hemispheres, first caudalwards and subsequently ventralwards and rostralwards, the retrocommissural part of the hippocampus (pars retrocommissuralis hippocampi) becomes situated in the temporal lobe (see ten Donkelaar et al., 2014). Rudiments of the supracommissural part of the hippocampus (pars supracommissuralis hippocampi) can be found above the corpus callosum as the indusium griseum (indusium griseum), a thin cell layer, flanked by the lateral longitudinal stria of Lancisi (stria longitudinalis lateralis), also known as the taenia tecti, and the medial longitudinal stria of Lancisi (stria longitudinalis medialis), also known as the taenia libera. The precommissural part of the hippocampus (pars precommissuralis hippocampi) disappears.

Macroscopically, the following parts of the hippocampus can be distinguished (Duvernoy, 1998; Insausti and Amaral, 2012; ten Donkelaar et al., 2018): (1) the pes hippocampi or pes of the hippocampus (pes hippocampi) showing the hippocampal 
digitations (digitationes hippocampi); (2) the head or anterior segment (caput or pars anterior); (3) the body or middle segment (corpus or pars media); (4) the tail or posterior segment (cauda or pars posterior); and (5) the gyri of Andreas Retzius or subsplenial gyri (dentes subiculi or gyri subspleniales) described by Gustav Retzius (Retzius, 1896) in honor of his father Anders Adolf, a series of small bumps marking the caudal limit of the CA1 field. Here, the parahippocampal gyrus meets the retrosplenial region caudally. Two obliquely oriented small gyri are located deep to the gyri of Andreas Retzius. The medial one is the fasciola cinerea (fasciola cinerea), the visible caudal end of the dentate gyrus as described by Giacomini (1884) and Klingler (1948). The lateral gyrus, corresponding to the caudal end of the CA3 field, is the fasciolar gyrus (gyrus fasciolaris).

\section{CONCLUSIONS}

In this review, an attempt for a common terminology for the cerebral gyri and sulci is presented, largely following the recently published Terminologia Neuroanatomica (TNA, 2017). The differences found in the modern literature mainly concern:

1. The use of the term fissure for certain deep sulci; here, it is advocated to restrict the term fissure to the interhemispheric fissure, and to use the term sulcus for all other grooves;

\section{REFERENCES}

Allison, A. C. (1954). The secondary olfactory areas in the human brain. J. Anat. $88,481-488$.

Alves, R. V., Ribas, G. C., Párraga, R. G., and de Oliveira, E. (2012). The occipital lobe convexity sulci and gyri. J. Neurosurg. 116, 1014-1023. doi: 10.3171/2012.1.JNS11978

Amunts, K., Schleicher, A., Bürgel, U., Mohlberg, U., Uylings, H. B., and Zilles, K. (1999). Broca's region revisited: cytoarchitecture and intersubject variability. J. Comp. Neurol. 412, 319-341.

Amunts, K., and Zilles, K. (2012). Architecture and organizational principles of Broca’s region. Trends Cogn. Sci. 16, 418-426. doi: 10.1016/j.tics.2012.06.005

Augustinack, J. C., Huber, K. E., Stevens, A. A., Roy, M., Frosch, M. P., van der Kouwe, A. J. W., et al. (2013). Predicting the location of human perirhinal cortex, Brodmann's area 35, from MRI. Neuroimage 64, 32-42. doi: 10.1016/j.neuroimage.2012.08.071

Blaizot, X., Mansilla, F., Insausti, A. M., Constans, J. M., Salinas-Alamán, A., PrõSistiaga, P., et al. (2010). The human parahippocampal region: I. temporal pole cytoarchitectonics and MRI correlation. Cereb. Cortex 20, 2198-2222. doi: 10.1093/cercor/bhp289

Bludau, S., Eickhoff, S. B., Mohlberg, H., Caspers, S., Laird, A. R., Fox, P. T., et al. (2014). Cytoarchitecture, probability maps and functions of the human frontal pole. Neuroimage 93, 260-275. doi: 10.1016/j.neuroimage.2013.05.052

BNA, Basle Nomina Anatomica (1895). Published by W. His: Die anatomische Nomenclatur. Nomina anatomica. Verzeichnis der von der Anatomischen Gesellschaft auf ihrer IX. Versammlung in Basel angenommenen Namen. Arch. Anat. Physiol., Anat. Abth., Suppl.-Bd. Leipzig: Veit, 1-180.

Braak, H., and Braak, E. (1992). The human entorhinal cortex: normal morphology and lamina-specific pathology in various diseases. Neurosci. Res. 15, 6-31. doi: 10.1016/0168-0102(92)90014-4

Brissaud, E. (1893). Anatomie du Cerveau de L'homme: Morphologie des Hémisphères Cérébraux, ou Cerveau Proprement Dit. Paris: Masson.

Broca, P. (1863). Localisation des fonctions cérébrales. Siège de la faculté du langage articulé. Bull. Soc. Anthropol. Paris 4, 200-208.

Broca, P. (1878a). Nomenclature cérébrale: Dénomination et subdivision des hémisphères et des anfractuosités de la surface. Rev. Anthropol. 2, 193-236.
2. The use of the topographical terms lateral and medial occipitotemporal gyri for the fusiform gyrus and the lingual gyrus, respectively.

3. These terms and some other frequently used terms are placed as synonyms, both in English and Latin in the TNA, and are summarized in Tables $\mathbf{1}-\mathbf{3}$.

4. We suggest a simple system of abbreviations with capitals for gyri and small letters for sulci.

5. In the near future, several new subdivisions will have to be included. The TNA database at the FIPAT websites (www. unifr.ch/ifaa; http://FIPAT.library.dal.ca) will be regularly updated.

\section{AUTHOR CONTRIBUTIONS}

All authors listed have made a substantial, direct and intellectual contribution to the work, and approved it for publication.

\section{SUPPLEMENTARY MATERIAL}

The Supplementary Material for this article can be found online at: https://www.frontiersin.org/articles/10.3389/fnana. 2018.00093/full\#supplementary-material

Broca, P. (1878b). Anatomie comparée des circonvolutions cérébrales. Le grand lobe limbique et la scissure limbique dans la série des mammifères. Rev. Anthropol. 2, 385-498.

Brodmann, K. (1909). Vergleichende Lokalisationslehre der Grosshirnrinde in ihren Prinzipien dargestellt auf Grund des Zellenbaues. Transl. by L.J. Garey in English (1999) Brodmann's Localisation in the Cerebral Cortex. Leipzig, Barth, London: Imperial College Press.

Caspers, J., Amunts, K., and Zilles, K. (2012). "Posterior parietal cortex", in The Human Nervous System, 3rd ed., eds J. K. Mai and G. Paxinos (Amsterdam: Elsevier), 1036-1053.

Caspers, S., Zilles, K., Eickhoff, S. B., Schleicher, A., Mohlberg, H., and Amunts, K. (2013). Cytoarchitectonical analysis and probabilistic mapping of two extrastriate areas of the human fusiform gyrus. Brain Struct. Funct. 218, 511-526. doi: 10.1007/s00429-012-0411-8

Chau, A. M., Stewart, F., and Gragnaniello, C. (2014). Sulcal and gyral anatomy of the basal occipito-temporal lobe. Surg. Radiol. Anat. 36, 959-965. doi: 10.1007/s00276-014-1294-6

Chiavaras, M. M., and Petrides, M. (2000). Orbitofrontal sulci of the human and macaque monkey. J. Comp. Neurol. 422, 35-54. doi: 10.1002/(SICI)10969861(20000619)422:1\&lt;35::AID-CNE3\&gt;3.0.CO;2-E

Choi, H. J., Zilles, K., Mohlberg, H., Schleicher, A., Fink, G. R., Armstrong, E., et al. (2006). Cytoarchitectonic identification and probabilistic mapping of two distinct areas within the anterior ventral bank of the human intraparietal sulcus. J. Comp. Neurol. 495, 53-69. doi: 10.1002/cne.20849

Cikla, U., Menekse, G., Quraishi, A., Neves, G., Keles, A., Liu, C., et al. (2016). The sulci of the inferior surface of the temporal lobe: An anatomical study. Clin. Anat. 29, 932-942. doi: 10.1002/ca.22767

Collins, D. L. (1994). 3D Model-Based Segmentation of Individual Brain Structures From Magnetic Resonance Imaging Data. PhD thesis, McGill University.

Collins, D. L., Zijdenbos, A. P., Kollokian, V., Sled, J. G., Kabani, N. J., Holmes, C. J., et al. (1998). Design and construction of a realistic digital brain phantom. IEEE Trans. Med. Imag. 17, 463-468. doi: 10.1109/42.712135

Dejerine, J. (1895). Anatomie des Centres Nerveux, Vol 1. Paris: Rueff.

Ding, S.-L., Royall, J.,l., Sunkin, S. M., Ng, L., Facer, B. A. C., Lesnar, P., et al. (2016). Comprehensive cellular-resolution atlas of the adult human brain. J. Comp. Neurol. 524, 3127-3481. doi: 10.1002/cne.24080 
Ding, S.-L., and Van Hoesen, G. W. (2010). Borders, extent, and topography of human perirhinal cortex as revealed using multiple modern neuroanatomical and pathological markers. Hum. Brain Mapp. 31, 1359-1379. doi: 10.1002/hbm.20940

Ding, S.-L., Van Hoesen, G. W., Cassell, M. D., and Poremba, A. (2009). Parcellation of human temporal polar cortex: a combined analysis of multiple cytoarchitectonic, chemoarchitectonic, and pathological markers. J. Comp. Neurol. 514, 595-623. doi: 10.1002/cne.22053

Duvernoy, H. (1992). Le Cerveau Humain. Surface, Coupes Sériée Tridimensionelles et IRM. Berlin; New York, NY: Springer.

Duvernoy, H. (1998). The Human Hippocampus. Functional Anatomy, Vascularization and Serial Sections With MRI, 2nd ed. Berlin; New York, NY: Springer.

Eberstaller, O. (1884). Zur Oberflächenanatomie der Grosshirnhemisphären. Wien. Med. Bl. 7, 479-482, 542-582, 644-646.

Eberstaller, O. (1890). Das Stirnhirn. Ein Beitrag zur Anatomie der Oberfläche des Grosshirns. Wien: Urban \& Schwarzenberg.

Ecker, A. (1869). Die Hirnwindungen des Menschen. Braunschweig: Vieweg.

Eickhoff, S. B., Amunts, K., Mohlberg, H., and Zilles, K. (2006b). The human parietal operculum. II. Stereotaxic maps and correlation with functional imaging. Cereb. Cortex 16, 268-279. doi: 10.1093/cercor/bhi106

Eickhoff, S. B., Schleicher, A., Zilles, K., and Amunts, K. (2006a). The human parietal operculum. I. cytoarchitectonic mapping of subdivisions. Cereb. Cortex 16, 254-267. doi: 10.1093/cercor/bhi105

Eickhoff, S. B., Stephan, K. E., Mohlberg, H., Grefkes, C., Fink, G. R., Amunts, K., et al. (2005). A new SPM toolbox for combining probabilistic cytoarchitectonic maps and functional imaging data. Neuroimage 25, 1325-1335. doi: 10.1016/j.neuroimage.2004.12.034

Galaburda, A. M., Sanides, F., and Geschwind, N. (1978). Human brain: cytoarchitectonic left-right asymmetries in the temporal speech region. Arch. Neurol. 35, 812-817. doi: 10.1001/archneur.1978.00500360036007

Gastaut, H., and Lammers, H. J. (1961). Anatomie du Rhinencéphale. Paris: Masson.

Geschwind, N., and Levitsky, W. (1968). Human brain: left-right asymmetries in temporal speech region. Science 161, 186-187. doi: $10.1126 /$ science.161.3837.186

Giacomini, C. H. (1884). Fascia dentata du grand hippocampe dans le cerveau de l'homme. Arch. Ital. Biol. 5, 1-16, 205-209, 396-417.

Gratiolet, L. P. (1854). Mémoire Sur Les Plis Cérébraux de L’homme et Des Primates. Paris: Bertrand.

Hanke, J. (1997). Sulcal pattern of the anterior parahippocampal gyrus in the human adult. Ann. Anat. 179, 335-339. doi: 10.1016/S0940-9602(97)80071-4

Heimer, L., de Olmos, J., Alheid, G. F., Pearson, J., Sakamoto, N., Marksteiner, J., et al. (1999). The human basal forebrain, Part 2. Handb. Chem. Neuroanat. 15, 57-226. doi: 10.1016/S0924-8196(99)80024-4

Heimer, L., Van Hoesen, G. W., and Rosene, D. L. (1977). The olfactory pathways and the anterior perforated substance in the primate brain. Int. J. Neurosci. 12, 42-52.

Heimer, L., Van Hoesen, G. W., Trimble, M., and Zahm, D. S. (2008). Anatomy of Neuropsychiatry. Amsterdam: Elsevier.

Heschl, R. L. (1878). Über Die Vordere Quere Schläfenwindung des Menschlichen Grosshirns. Wien: Braumüller.

Hill, J., Dierker, D., Neil, J., Inder, T., Knutsen, A., Harwell, J., et al. (2010). A surface-based analysis of hemispheric asymmetries and folding of cerebral cortex in term-born human infants. J. Neurosci. 30:2268-2276. doi: 10.1523/JNEUROSCI.4682-09.2010

Holmes, C. J., Hoge, R., Collins, L., Woods, R., Toga, A. W., and Evans, A. C. (1998). Enhancement of MR images using registration for signal averaging. J. Comput. Assist. Tomogr. 22, 324-333. doi: 10.1097/00004728-199803000-00032

Huntgeburth, S. C., and Petrides, M. (2012). Morphological patterns of the collateral sulcus in the human brain. Eur. J. Neurosci. 35, 1295-1311. doi: 10.1111/j.1460-9568.2012.08031.x

Huschke, E. (1854). Schädel, Hirn und Seele des Menschen und der Thiere nach Alter, Geschlecht und Race. Jena: Mauke.

Ide, A., Dolezal, C., Fernández, M., Labb,é, E., Mandujano, R., Montes, S., et al. (1999). Hemispheric differences in variability of fissural patterns in parasylvian and cingulate regions of human brains. J. Comp. Neurol. 410, 235-242. doi: 10. 1002/(SICI)1096-9861(19990726)410:2<235::AID-CNE5>3.3.CO;2-7
Insausti, R., and Amaral, D. G. (2012). "Hippocampal formation”, in The Human Nervous System, 3rd ed, eds J. K. Mai and G. Paxinos (Amsterdam: Elsevier), 896-942.

Insausti, R., Muñoz-López, M., Insausti, A. M., and Artachon-Pérula, E. (2017). The human periallocortex: Layer pattern in presubiculum, parasubiculum and entorhinal cortex. A review. Front. Neuroanat. 11:84. doi: 10.3389/fnana.2017.00084

Insausti, R., Tuñón, T., Sobreviela, T., and Insausti, A. M. (1995). The human entorhinal cortex: a cytoarchitectonic analysis. J. Comp. Neurol. 355, 171-198. doi: 10.1002/cne.903550203

Jensen, J. (1871). Abhandlung über die Furchen und Windungen der menschlichen Grosshirnhemisphären. Allg. Z. Psychiatr. 27, 473-516.

JNA, Jenaer Nomina Anatomica (1936). Approved June 1935 by the Anatomische Gesellschaft in Jena, Published Early 1936 by H. Stieve. Jena: Fischer.

Klingler, J. (1948). Die Makroskopische Anatomie der Ammonsformation. Denkschr. Schweiz. Naturforsch. Ges., Vol 78. Zürich: Fretz.

Lorenz, S., Weiner, K. S., Caspers, J., Mohlberg, H., Schleicher, A., Bludau, S., et al. (2017). Two new cytoarchitectonic areas on the human mid-fusiform gyrus. Cereb. Cortex 27, 373-385. doi: 10.1093/cercor/bhv225

Mai, J. K., and Majtanik, M. (2017). Human Brain in Standard MNI Space. A Comprehensive Pocket Atlas. London, San Diego, CA: Academic Press/Elsevier.

Mai, J. K., Majtanik, M., and Paxinos, G. (2016). Atlas of the Human Brain, 4th Edn. San Diego, CA: Academic Press/Elsevier.

Mai, J. K., and Paxinos, G. eds. (2012). The Human Nervous System, 3rd ed. Amsterdam: Elsevier.

Malikovic, A., Vucetic, B., Milisavljevic, M., Tosevski, J., Sazdanovic, P., Milojevic, B., et al. (2012). Occipital sulci of the human brain: variability and morphometry. Anat. Sci. Int. 87,61-70. doi: 10.1007/s12565-011-0118-6

Marie, D., Jobard, G., Crivello, F., Perchey, G., Petit, L., Mellet, E., et al. (2015). Descriptive anatomy of Heschl's gyri in 430 healthy volunteers, including 198 left-handers. Brain Struct. Funct. 220, 729-743. doi: 10.1007/s00429-013-0680-x

Mazziota, J., Toga, A., Evans, A., Fox, P., Lancaster, J., Zilles, K., et al. (2001). A probabilistic atlas and reference system for the human brain: international consortium for brain mapping (icbm). Philos. Trans. R. Soc. Lond. B. Biol. Sci. 356, 1293-1322. doi: 10.1098/rstb.2001.0915

Morel, A., Gallay, M. N., Baechler, A., Wyss, M., and Gallay, D. S. (2013). The human insula: architectonic organization and postmortem MRI registration. Neuroscience 236, 117-135. doi: 10.1016/j.neuroscience.2012.12.076

Naidich, T. P., Kang, E., Fatterpekar, G. M., Delman, B. N., Gultekin, S. H., Wolfe, D., et al. (2004). The insula: anatomic study and MR imaging display at $1.5 \mathrm{~T}$. AJNR Am. J. Neuroradiol. 25, 222-232.

Nieuwenhuys, R., Broere, C. A. J., and Cerliani, L. (2015). A new myeloarchitectonic map of the human neocortex based on data from the Vogt-Vogt school. Brain Struct. Funct. 220, 2551-2573. doi: 10.1007/s00429-014-0806-9

Nieuwenhuys, R., Voogd, J., and van Huyzen, C. (2008). The Human Central Nervous System, 4th Edn. Heidelberg: Springer.

Öngur, D., Ferry, A. T., and Price, J.L. (2003). Architectonic subdivision of the human prefrontal cortex. J. Comp. Neurol. 460, 425-449. doi: 10.1002/cne.10609

Ono, M., Kubik, S., and Abernathey, C. D. (1990). Atlas of the Cerebral Sulci. Stuttgart; New York, NY: Thieme.

Pansch, A. G. (1868). Über die typische Anordnung der Furchen und Windungen auf den Grosshirnhemisphären des Menschen und der Affen. Arch. Anthropol. 3, 227-257.

Pansch, A. G. (1879). Die Furchen und Wülste am Grosshirn des Menschen. Berlin: Oppenheim.

Paus, T., Tomaiuolo, F., Otaky, N., MacDonald, D., Petrides, M., Atlas, J., et al. (1996). Human cingulate and paracingulate sulci: pattern, variability, asymmetry, and probabilistic map. Cereb. Cortex 6, 207-214. doi: 10.1093/cercor/6.2.207

Petrides, M., and Pandya, D. N. (2012). "The frontal cortex," in The Human Nervous System, 3rd Edn., eds J. K. Mai and G. Paxinos (Amsterdam: Elsevier), 988-1011.

PNA, Parisiensia Nomina Anatomica (1955). Approved by the Sixth International Congress of Anatomists held at Paris 1955, privately circulated; PNA printed by Spottiswoode, Ballantine \& Co, London; revised editions appeared as Nomina 
Anatomica (2nd ed 1961, 3rd 1966, 4th 1977, published by Excerpta Medica, Amsterdam, a 5th ed 1983 and a 6th ed 1989, published by Williams \& Wilkins, Baltimore, and Churchill Livingstone, Edinburgh, respectively).

Retzius, G. (1896). Das Menschenhirn: Studien in der Makroskopischen Morphologie. Stockholm: Norstedt.

Rhoton, A. L. Jr. (2007). The cerebrum. Neurosurgery 61 (SHC Suppl 1), SHC37SHC119. doi: 10.1227/01.NEU.0000255490.88321.CE

Rizzolatti, G., Luppino, G., and Matelli, M. (1998). The organization of the cortical motor system: new concepts. Electroencephalogr. Clin. Neurophysiol. 106, 283-296. doi: 10.1016/S0013-4694(98)00022-4

Rolls, E. T., Joliot, M., and Tzourio-Mazoyer, N. (2015). Implementation of a new parcellation of the orbitofrontal cortex in the automated anatomical labeling atlas. Neuroimage 122, 1-5. doi: 10.1016/j.neuroimage.2015.07.075

Rose, M. (1926). Über das histogenetische Prinzip der Einteilung der Grosshirnrinde. J. Psychol. Neurol. 32, 97-160.

Rose, M. (1935). "Cytoarchitektonik und myeloarchitektonik der Großhirnrinde," in Handbuch der Neurologie, Bd. 1, eds O. Bumke and O. Förster (Berlin: Springer), 588-778.

Rosenke, M., Weiner, K. S., Barrett, M. A., Zilles, K., Amunts, K., Goebel, R., et al. (2018). A cross-validated cytoarchitectonic atlas of the human ventral visual stream. Neuroimage 170, 257-270. doi: 10.1016/j.neuroimage.2017.02.040

Rumeau, C., Tzourio, N., Murayama, N., Peretti-Viton, P., Levrier, O., Joliot, M., et al. (1994). Location of hand function in the sensorimotor cortex: MR and functional correlation. AJNR Am. J. Neuroradiol. 15, 567-572.

Scheperjans, F., Eickhoff, S. B., Hömke, L., Mohlberg, H., Hermann, K., Amunts, K., et al. (2008a). Probabilistic maps, cytoarchitectonic morphology, and variability of areas in human superior parietal cortex. Cereb. Cortex 18, 2141-2157. doi: 10.1093/cercor/bhm241

Scheperjans, F., Hermann, K., Eickhoff, S. B., Amunts, K., Schleicher, A., and Zilles, K. (2008b). Observer-independent cytoarchitectonic mapping of the human superior parietal cortex. Cereb. Cortex 18, 846-867. doi: $10.1093 /$ cercor/bhm116

Seitz, R. J., and Binkofski, F. (2003). Modular organization of parietal lobe functions revealed by functional activation studies. Adv. Neurol. 93, 281-292.

Stephan, H. (1975). Allocortex. Handbuch der mikroskopischen Anatomie des Menschen, Vol 4, Teil 9. Heidelberg: Springer.

Suzuki, W. A., and Amaral, D. G. (1994). The perirhinal and parahippocampal cortices of the macaque monkey: cortical afferents. J. Comp. Neurol. 350, 497-533. doi: 10.1002/cne.903500402

TA, Terminologia Anatomica (1998). International Anatomical Terminology. Stuttgart; New York, NY: FCAT, Thieme.

Talairach, J., and Tournoux, P. (1988). Co-planar Stereotaxic Atlas of the Human Brain 3-Dimensional Proportional System: An approach to cerebral imaging. Stuttgart; New York, NY: Thieme.

Tamraz, J. C., and Comair, Y. G. (2000). Atlas of Regional Anatomy of the Brain Using MRI. Berlin; New York, NY: Springer.

ten Donkelaar, H. J. (2011). Clinical Neuroanatomy: Brain Circuitry and its Disorders. Heidelberg; Dordrecht; London; New York, NY: Springer.

ten Donkelaar, H. J., Broman, J., Neumann, P. E., Puelles, L., Riva, A., Tubbs, R. S., et al. (2017). Towards a Terminologia Neuroanatomica. Clin. Anat. 30, 145-155. doi: 10.1002/ca.22809

ten Donkelaar, H. J., Kachlík, D., and Tubbs, S. T. (2018). An Illustrated Terminologia Neuroanatomica. A Concise Encyclopedia of Human Neuroanatomy. Heidelberg; New York, NY: Springer.

ten Donkelaar, H. J., Lammens, M., and Hori, A. (2014). Clinical Neuroembryology: Development and Developmental Disorders of the Human Central Nervous System, 2nd ed. Heidelberg; New York, NY; Dordrecht; London: Springer.

Testut, L., and Latarjet, A. (1948). Traité d'anatomie Humaine, Vol. 2. Paris: Doin.

TNA, Terminologia Neuroanatomica (2017). FIPAT.library.dal.ca. Dalhousie: Federative International Programme for Anatomical Terminology.

Toga, A. W., and Thompson, P. M. (2003). Mapping brain asymmetry. Nat. Rev. Neurosci. 4:37-48. doi: 10.1038/nrn1009

Türe, U., Yaşargil, D. C. H., Al-Mefti, O., and Yaşargil, M. C. (1999). Topographic anatomy of the insular region. J. Neurosurg. 90, 720-733. doi: $10.3171 /$ jns.1999.90.4.0720
Tzourio-Mazoyer, N., Landeau, B., Papathanassiou, D., Crivello, F., Etard, O., Delcroix, N., et al. (2002). Automated anatomical labeling of activations in SPM using a maroscopic anatomical parcellation of the MNI MRI single-subject brain. Neuroimage 15, 273-289. doi: 10.1006/nimg.200 1.0978

Tzourio-Mazoyer, N., and Mazoyer, B. (2017). Variations of planum temporale asymmetries with Heschl's gyri duplications and association with cognitive abilities: MRI investigation of 428 healthy volunteers. Brain Struct. Funct. 222, 2711-2726. doi: 10.1007/s00429-017-1367-5

Van Essen, D. C. (2005). A population-average, landmark- and surfacebased (pals) atlas of the human cerebral cortex. Neuroimage 28, 635-662. doi: 10.1016/j.neuroimage.2005.06.058

Van Essen, D. C., Glasser, M. F., Dierker, D. L., Harwell, J., and Coalson, T. (2012). Parcellation and hemispheric asymmetries of human cerebral cortex analysed on surface-based atlases. Cereb. Cortex 22, 2241-2262. doi: 10.1093/cercor/bhr291

Vicq d'Azyr, F. (1786). Traité D'anatomie et de Physiologie, Avec des Planches Coloriées Réprésentant au Naturel les Divers Organes de L'homme et des Animaux, Tome I. Paris: Didot.

Vogt, B. A., and Palomero-Gallagher, N. (2012). "Cingulate cortex," in The Human Nervous System, 3rd ed, eds J. K. Mai and G. Paxinos (Amsterdam: Elsevier), 943-987.

Vogt, C., and Vogt, O. (1919). Allgemeinere ergebnisse unserer Hirnforschung. J. Psychol. Neurol. 25, 279-461.

von Economo, C., and Horn, L. (1930). Über Windingsrelief, Maße und Rindenarchitektonik der Supratemporalfläche. Z. Ges. Neurol. Psychiatr. 130, 678-757.

von Economo, C., and Koskinas, G. N. (1925). Die Cytoarchitektonik der Hirnrinde des erwachsenen Menschen. In English transl. by L.C. Triarhou (2008). Atlas of Cytoarchitectonics of the Adult Human Cerebral Cortex. Berlin; Heidelberg; New York, NY; Basel: Karger, Springer.

von Soemmerring, S. T. (1791). Vom Baue des Menschlichen Körpers, Vol 5: Hirnlehre und Nervenlehre. Frankfurt am Main: Varrentrap \& Wenner.

Wang, L., Mruczek, R. E., Arcaro, M. J., and Kastner, S. (2015). Probabilistic maps of visual topography in human cortex. Cereb. Cortex 25, 3911-3931. doi: 10.1093/cercor/bhu277

Wernicke, C. (1874). Der aphasische Symptomenkomplex. Eine Psychologische Studie Auf Anatomischer Basis. Breslau: Cohn \& Weigert.

Wernicke, C. (1876). Das Urwindungssystem des menschlichen Gehirns. Arch. Psychiatr. Nervenkr. 6, 298-326. doi: 10.1007/BF022 30815

Yousry, T. A., Schmid, U. D., Alkadhi, H., Schmidt, D., Peraud, A., Buettner, A., et al. (1997). Localization of the hand motor area to a knob on the precentral gyrus. a new landmark. Brain 120, 141-157.

Zilles, K. (2004). "Architecture of the human cerebral cortex. regional variation and laminar organization," in The Human Nervous System, 2nd ed, eds G. Paxinos and J.K. Mai (Amsterdam: Elsevier), 997-1055.

Zilles, K., and Amunts, K. (2012). "Architecture of the human cerebral cortex," in The Human Nervous System, 3rd ed, eds J. K. Mai and G. Paxinos (Amsterdam: Elsevier), 836-895.

Zlatkina, V., and Petrides, M. (2014). Morphological patterns of the intraparietal sulcus and the anterior intermediate parietal sulcus of Jensen in the human brain. Proc. Roy. Soc. B 281:20141493. doi: 10.1098/rspb.2014.1493

Conflict of Interest Statement: The authors declare that the research was conducted in the absence of any commercial or financial relationships that could be construed as a potential conflict of interest.

Copyright (C) 2018 ten Donkelaar, Tzourio-Mazoyer and Mai. This is an open-access article distributed under the terms of the Creative Commons Attribution License (CC $B Y)$. The use, distribution or reproduction in other forums is permitted, provided the original author(s) and the copyright owner(s) are credited and that the original publication in this journal is cited, in accordance with accepted academic practice. No use, distribution or reproduction is permitted which does not comply with these terms. 